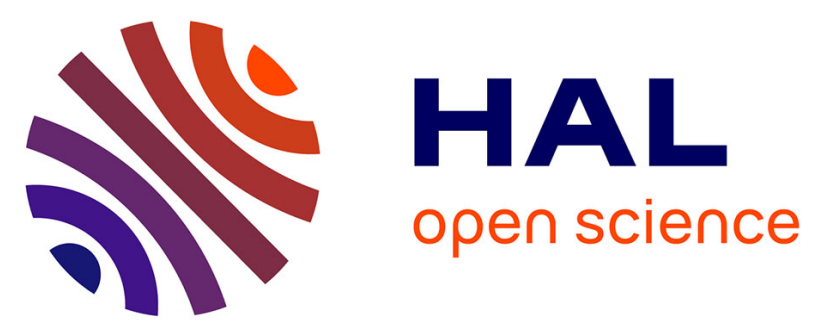

\title{
Effects of a Quaternary Ammonium Salt on the Growth, Wettability, and Agglomeration of Structure II Hydrate Crystals
}

Henry Delroisse, Jean-Philippe Torre, Christophe Dicharry

\section{- To cite this version:}

Henry Delroisse, Jean-Philippe Torre, Christophe Dicharry. Effects of a Quaternary Ammonium Salt on the Growth, Wettability, and Agglomeration of Structure II Hydrate Crystals. Energy \& Fuels, 2018, 32 (12), pp.12277-12288. 10.1021/acs.energyfuels.8b02980 . hal-01984991

\section{HAL Id: hal-01984991 https://hal.science/hal-01984991}

Submitted on 17 Jan 2019

HAL is a multi-disciplinary open access archive for the deposit and dissemination of scientific research documents, whether they are published or not. The documents may come from teaching and research institutions in France or abroad, or from public or private research centers.
L'archive ouverte pluridisciplinaire HAL, est destinée au dépôt et à la diffusion de documents scientifiques de niveau recherche, publiés ou non, émanant des établissements d'enseignement et de recherche français ou étrangers, des laboratoires publics ou privés. 


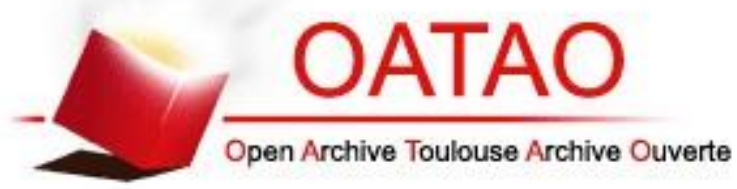

\section{Open Archive Toulouse Archive Ouverte}

OATAO is an open access repository that collects the work of Toulouse researchers and makes it freely available over the web where possible

This is an author's version published in: http://oatao.univ-toulouse.fr/21609

Official URL: https://doi.org/10.1021/acs.energyfuels.8b02980

\section{To cite this version:}

Delroisse, Henry and Torré, Jean-Philippe $\leftrightarrows$ and Dicharry, Christophe Effects of a Quaternary Ammonium Salt on the Growth, Wettability, and Agglomeration of Structure II Hydrate Crystals. (2018) Energy \& Fuels, 32 (12). 12277-12288. ISSN 0887-0624

Any correspondence concerning this service should be sent to the repository administrator: tech-oatao@listes-diff.inp-toulouse.fr 


\title{
Effects of a Quaternary Ammonium Salt on the Growth, Wettability, and Agglomeration of Structure II Hydrate Crystals
}

\author{
H. Delroisse, J.-P. Torré, ${ }^{(1)}$ and C. Dicharry*0 \\ CNRS/TOTAL/UNIV PAU \& PAYS ADOUR/E2S UPPA, Laboratoire des Fluides Complexes et Leurs Réservoirs IPRA, \\ UMR5150, 64000, Pau, France
}

Supporting Information

\begin{abstract}
This work studied the effects of a water soluble quaternary ammonium salt (called DA S0) on the growth, wettability, and agglomeration of cyclopentane $(\mathrm{CP})$ hydrate crystals and methane $\left(\mathrm{CH}_{4}\right) /$ propane $\left(\mathrm{C}_{3} \mathrm{H}_{8}\right)$ hydrate crystals. The impact on these properties of adding $4 \mathrm{wt} \% \mathrm{NaCl}$ to the $\mathrm{DA} 50$ solution was also investigated. The hydrates were formed from water/CP, water $/(\mathrm{CP}+n$ octane $(n \mathrm{C} 8))$, and water $/(\mathrm{CP}+n$ dodecane $(n \mathrm{C12}))$ mixtures at atmospheric pressure and from a water $/ n \mathrm{C} 8 /\left(\mathrm{CH}_{4}+\mathrm{C}_{3} \mathrm{H}_{8}\right)$ mixture under pressure (about 67 bar). Experiments were performed at a subcooling of $6^{\circ} \mathrm{C}$ in the case of the $\mathrm{CP}$ hydrates and $9-10^{\circ} \mathrm{C}$ in the case of the $\mathrm{CH}_{4} / \mathrm{C}_{3} \mathrm{H}_{8}$ hydrates. In both hydrate systems, adding $\mathrm{NaCl}$ to the surfactant solution of 0.1 or 1 wt \% DA 50 led to the formation of individual oil wettable pyramidal crystals. Without salt, the hydrate formed a water wettable shell that covered the water/oil interface just as the system without surfactant did. The antiagglomeration performance of the 1 wt \% DA 50 solution was evaluated by performing torque measurements in an agitated batch reactor at a water cut of $30 \mathrm{vol} \%$. Without $\mathrm{NaCl}$, torque increased with the amount of $\mathrm{CP}$ hydrates. The system formed a nonflowable jelly like phase, with water as the continuous phase, until a phase inversion occurred. From there on torque significantly decreased and the system became a flowable dispersion of large hydrate particles $(\sim 700 \mu \mathrm{m})$ in the CP phase. With 4 wt $\% \mathrm{NaCl}$, the system consisted of small $(\sim 70 \mu \mathrm{m})$ hydrate particles dispersed in the CP phase and the torque signal remained constant throughout the hydrate crystallization process. The torque profiles obtained at concentrations of 0 or 4 wt $\%$ $\mathrm{NaCl}$ for the $\mathrm{CP}$ hydrates and the $\mathrm{CH}_{4} / \mathrm{C}_{3} \mathrm{H}_{8}$ hydrates were similar, suggesting analogous states for both systems. For both hydrate systems, adding $\mathrm{NaCl}$ to the $\mathrm{DA} 50$ solution led to the formation of oil wettable hydrates and drastically improved the antiagglomeration performance of the surfactant molecules, revealing a correlation between the formation of individual crystals and the antiagglomeration performance of the surfactant. The similarity between the growth patterns and shapes of the $\mathrm{CP}-$ hydrate crystals and the $\mathrm{CH}_{4} / \mathrm{C}_{3} \mathrm{H}_{8}$-hydrate crystals confirmed that $\mathrm{CP}$ hydrates are an interesting model for evaluating the antiagglomeration performance of surfactants.
\end{abstract}

\section{INTRODUCTION}

Gas hydrates are inclusion compounds composed of a network of water molecules (called hosts), forming cavities in which small molecules (called guests) are encapsulated. The guests are usually light hydrocarbon molecules such as methane, propane, or carbon dioxide. Gas hydrates usually require low temperature (a fewdegrees above $0^{\circ} \mathrm{C}$ ) and high pressure (a few dozen bars) conditions to form. Depending on the size of the guest molecules, gas hydrates can crystallize as structures I, II, or $\mathrm{H}$. Structure II (sII), composed of a unit cell with 136 water molecules forming 16 small pentagonal dodecahedron cavities and 8 large hexakaidecahedron cavities, is one of the most frequently found in oil and gas production. ${ }^{1}$

Crude oil production generally goes hand in hand with gas and water production. The presence of the three compounds associated with high pressure and low temperature conditions, as in the deep offshore for example, is generally conducive to hydrate formation. If hydrate crystals form and agglomerate, they can plug pipelines and cause production shutdowns, resulting in economic losses and safety problems.

Chemical additives can be used to prevent hydrate plug formation. ${ }^{2}$ They are divided into two main families: (i) thermodynamic hydrate inhibitors (THIs) (such as methanol or glycol), which are often used in large concentrations (several dozen wt \% relative to the water phase), and (ii) low dosage hydrate inhibitors (LDHIs), of which only small amounts are required (usually less than 1 wt \%) to achieve good protection against the risk of hydrate plug formation. LDHIs are subdivided into two groups: kinetic hydrate inhibitors (KHIs) and antiagglomerants (AAs). KHIs delay hydrate nucleation and/ or reduce hydrate growth rate. AAs do not prevent hydrate formation but limit the agglomeration ofhydrate particles. THIs, whose role is to prevent hydrate formation, are still the chemical additives most commonly used in the oil and gas industry for hydrate risk management. However, AAs are increasingly regarded as a robust and economical option for preventing hydrate blockage, especially for systems which are subject to high subcoolings (difference between the system temperature and the hydrate equilibrium temperature at system pressure), $\Delta T_{\text {sub }}\left(>10^{\circ} \mathrm{C}\right),{ }^{2}$ as in deep offshore production, for example, where KHIs generally do not work AAs are surface active agents, which, due to their interfacial activity, ${ }^{3}$ may promote the formation of emulsions. Several authors have reported that in oil dominated systems the formation of a stable water in oil (w/ 
o) emulsion can promote the dispersion of hydrate particles into the oil phase and prevent/limit their agglomeration. ${ }^{4-6}$ However, York and Firoozabadi (2008) demonstrated that a good antiagglomeration performance could be observed without a stable w/o emulsion.

Cyclopentane (CP) hydrates have been widely used to evaluate the performance of AAs. ${ }^{8,9}$ When combined with water, $\mathrm{CP}$ forms sII hydrates (as natural gas does) but at atmospheric pressure and moderately low temperatures (of less than 7-7.7 $\left.{ }^{\circ} \mathrm{C}\right) .{ }^{1,10,11} \mathrm{CP}$ hydrates have a stoichiometric $\mathrm{CP}$ : water molar ratio of $1: 17$. Because $\mathrm{CP}$ is almost insoluble in water $(156 \mathrm{ppm}$ at $\left.25^{\circ} \mathrm{C}\right),{ }^{12} \mathrm{CP}$-hydrate formation occurs at the water/oil (i.e., water/CP) interface, as is the case for most sII-hydrates involved in blockages. Moreover, when $\mathrm{CP}$ is used in large quantities, it can act both as the hydrate former and as the oil phase. Recently, Abojaladi and Kelland ${ }^{9}$ (2016) evaluated the performance of 26 surfactants (cationic, anionic, and nonionic) used as AAs on CP hydrates and natural gas hydrates in the presence of white spirit as the oil phase. They used two different experimental setups: agitated double walled glass beakers for the $\mathrm{CP}$-hydrate system and sapphire rocking cells for the gashydrate system. The authors found that the majority of the most efficient additives for both hydrate systems belonged to the cationic family.

One drawback of using CP hydrates as a model system for gas hydrates formed at high pressure is that the maximum subcooling before the possible formation of ice is only around $7{ }^{\circ} \mathrm{C}$. At low subcoolings, hydrate crystallization might be difficult to achieve, particularly if the AAs evaluated also have KHI properties. ${ }^{13}$ To avoid this problem, crystallization is often triggered by seeding the system with preformed $\mathrm{CP}$-hydrate crystals. $^{14}$

Because AAs are amphiphilic molecules, they position themselves at the water/gas or water/oil interface, where hydrate crystallization generally occurs, and can also be adsorbed onto the hydrate crystals, affecting their morphology. Several authors ${ }^{15-17}$ used CP hydrates to study the influence of surfactants on hydrate morphology. Without surfactants, it has been reported that polygonal hydrate crystals form a polycrystal line hydrate layer at the water/CP interface, while the presence of surfactants usually induces the formation of crystals of different shapes. In some cases, the hydrate crystals were seen to migrate from the water/CP interface to one of the adjacent phases: the aqueous phase if the adsorbed surfactant molecules made the crystals water wettable or the oil phase if the crystals were rendered oil wettable. For instance, Karanjkar et al. ${ }^{16}$ (2012) observed that the nonionic surfactant Span 80 used at $0.1 \mathrm{vol} \%$ in the oil phase triggered the growth of hollow conical crystals at subcoolings of more than $3.2^{\circ} \mathrm{C}$ and of plate like crystals at lower subcoolings. The hollow conical crystals became detached from the water/CP interface and then sank in the aqueous phase. Mitarai et al. ${ }^{15}$ (2015) studied the effect of Span 80, a naphthenic acid, and a polypropylene glycol (PPG) on the formation of CP hydrates. They reported different crystal growth behaviors depending on the additive and its concen tration at subcoolings between 1.3 and $4.2^{\circ} \mathrm{C}$. With $0.001 \mathrm{wt} \%$ of naphthenic acid or 0.001 and 0.01 wt \% of Span 80, they observed that the hydrate crystals became detached from the interface and sank in the aqueous phase, whereas with 0.001 and $0.01 \mathrm{wt} \%$ of PPG, a porous hydrate layer formed at the water/ CP interface. At higher concentrations (0.01 wt \%), the naphthenic acid inhibited hydrate formation. Delroisse et al. ${ }^{17}$ (2017) reported that $0.1-1$ wt \% of DA 50 (a quaternary ammonium salt) in the aqueous phase induced the formation of a hydrate shell, composed of an assembly of smooth and/or striated plates, at the water/CP interface at a subcooling of $6{ }^{\circ} \mathrm{C}$. With a lower concentration of DA 50 (0.01 wt \%), hydrate needles formed at the interface before sinking and aggregating into a thick unconsolidated layer in the aqueous phase.

Some authors studied the influence of surfactants on the morphology of sII gas hydrates. In the case of hydrates formed with a methane $\left(\mathrm{CH}_{4}\right)$ /propane $\left(\mathrm{C}_{3} \mathrm{H}_{8}\right)$ mixture in a system without surfactants at a subcooling of $13.1{ }^{\circ} \mathrm{C}$, Yoslim et al. ${ }^{18}$ (2010) reported that a shell formed at the water/gas interface and needles appeared in the aqueous phase. With anionic surfactants (sodium dodecyl, tetradecyl, or hexadecyl sulfates) they observed the formation of fibrous crystals at subcoolings between 3.6 and $13.1{ }^{\circ} \mathrm{C}$. Karanjkar et al. ${ }^{16}$ (2012) studied the effect of Span 80 ( $0.1 \mathrm{vol} \%$ of the oil phase) on the formation of $\mathrm{C}_{3} \mathrm{H}_{8}$ hydrates on a water drop immersed in a light mineral oil. They observed that fibrous crystals forming a porous structure developed into the drop, whereas without surfactant, a polycrystalline shell formed on the drop surface.

Cationic surfactants and more specifically quaternary ammonium salts are the type of AAs predominantly used in flow assurance to avoid hydrate problems. ${ }^{2}$ Their effectiveness is generally evaluated in the presence of salt because produced water (i.e., the water that is produced along with the oil and gas) always contains salt. Salt has both a thermodynamic effect (in that it shifts the hydrate equilibrium conditions to lower temperatures and higher pressures) and a kinetic effect (it slows down hydrate growth) on hydrate formation, both of which are intensified with the greater the salt concentration. As an example, the $\mathrm{CP}$-hydrate equilibrium temperature (noted $T_{\text {eq }}$ ) is about $7.2{ }^{\circ} \mathrm{C}$ without salt, $5.3{ }^{\circ} \mathrm{C}$ with 5 wt $\% \mathrm{NaCl}$, and -11.7 ${ }^{\circ} \mathrm{C}$ with 23 wt \% NaCl. ${ }^{16}$ Kishimoto et al. ${ }^{14}$ (2012) found that at $\Delta T_{\text {sub }}=6{ }^{\circ} \mathrm{C}$, the growth rate of hydrate crystals at the pure water/CP interface was reduced by factors of 2 and 7 by adding 3.5 and $10 \mathrm{wt} \% \mathrm{NaCl}$, respectively. In addition, the presence of salt is known to affect the interfacial properties of ionic surfactants. ${ }^{19-21}$ Consequently, salt can significantly modify the geometrical and physicochemical properties of hydrate crystals (such as morphology, size, and wettability), which may in turn affects the agglomeration of the hydrate particles. It is therefore of practical importance for the effect of a given surfactant on hydrate agglomeration to be studied in the presence and absence of salt. We showed in a previous study ${ }^{17}$ that adding 3 or 4 wt $\%$ $\mathrm{NaCl}$ to a solution containing 0.1 or 1 wt \% of DA 50 has a huge impact on the morphology and wettability of the $\mathrm{CP}$-hydrate crystals formed at a quiescent water/CP interface. Without $\mathrm{NaCl}$, we observed the formation of a hydrate layer composed of large water wettable hydrate plates that progressively covered the interface, whereas with 3 or $4 \mathrm{wt} \% \mathrm{NaCl}$ a multitude of small $(50-500 \mu \mathrm{m})$ individual pyramidal and CP wettable crystals formed at the interface, suggesting that this surfactant has interesting antiagglomeration properties in salt water.

The present work is a follow up to our previous study ${ }^{17}$ investigating the effects of $\mathrm{DA} 50$ and salt $(\mathrm{NaCl})$ on $\mathrm{CP}-$ hydrate growth at the water/oil interface. It examines and compares the effects of DA 50 on the morphology and wettability of hydrate crystals formed with $\mathrm{CP}$ (at atmospheric pressure) and with a $\mathrm{CH}_{4} / \mathrm{C}_{3} \mathrm{H}_{8}$ gas mixture (at about 67 bar). The antiagglomeration performance of this surfactant was evaluated for both hydrate systems. The influence of the nature of the oil phase ( $n$ octane, $n$ dodecane) on CP-hydrate morphology and the antiagglomeration performance of DA 50 
were also studied. The morphology of the hydrate crystals was determined by observing a quiescent water/oil interface under the microscope, and the antiagglomeration performance was studied in an agitated reactor for oil dominated systems containing $30 \mathrm{vol} \%$ of the aqueous solution. The effect of $\mathrm{NaCl}$ (at 0 and 4 wt \% of the aqueous phase) on the hydrate formation pattern, hydrate morphology, and antiagglomeration performance was investigated. Finally, the possible correlations between hydrate morphology, the wettability of the hydrate crystals formed, and the antiagglomeration performance of the surfactant obtained for both hydrate systems were discussed.

\section{EXPERIMENTAL METHODS}

2.1. Materials. Cyclopentane (reagent grade, $98 \%), n$ octane $(99 \%$ pure, referred to as $n$ C 8 ), and $n$ dodecane (99\% pure, referred to as $n$ C12) were supplied by Acros Organics. Deionized water (resistivity of 18.2 $\mathrm{M} \Omega . \mathrm{cm}$ ), produced by a Purelab laboratory water purification system, was used to prepare the surfactant solutions. The hydrate forming gas is a binary mixture of $84 \mathrm{~mol} \%$ (relative uncertainty of $\pm 2 \%)$ methane $\left(\mathrm{CH}_{4}\right)$ and $16 \mathrm{~mol} \%$ propane $\left(\mathrm{C}_{3} \mathrm{H}_{8}\right)$ supplied by Linde. The ionic surfactant used in the study is Noramium DA 50 (benzyl dodecyldimethylazanium chloride $\left(\mathrm{C}_{21} \mathrm{H}_{38} \mathrm{ClN}\right)$, see the formula in Supporting Information A), a quaternary ammonium salt that is provided by ARKEMA CECA. DA 50 is water soluble, and its critical micelle concentration (CMC) in pure water is $0.15 \pm 0.05 \mathrm{wt} \%$ at $25{ }^{\circ} \mathrm{C} .{ }^{17} \mathrm{DA} 50$ induces the formation of oil in water emulsions in all of the systems used to evaluate the antiagglomeration performance in the agitated reactor. This observation is in accordance with Bancroft's rule which states that "the phase in which a surfactant is more soluble (here the water phase) constitutes the continuous phase". ${ }^{22}$ However, we observed that the stability of the emulsions formed decreased in the presence of $\mathrm{NaCl}$ (see Table S1 in Supporting Information B).

2.2. Microscopic Observation of Hydrate Formation. $C P$ Hydrates. CP-hydrate growth and morphology were studied by microscopic observation of the interface between the water phase and the $\mathrm{CP}$ phase. The $\mathrm{CP}$ and water were previously introduced into a cylindrical glass tube placed in a metal jacketed vessel, in which a water-glycol mixture was circulated to control the temperature (Figure 1). The details of the experimental setup are presented in our previous article. ${ }^{17}$ In short, about $5 \mathrm{~cm}^{3}$ of the aqueous solution and $3 \mathrm{~cm}^{3}$ of CP were successively introduced into the glass tube at room temperature. The glass tube was then covered with a glass cap to limit CP evaporation. The temperature of the system was decreased to a target temperature within the hydrate stability domain. After stabilization at

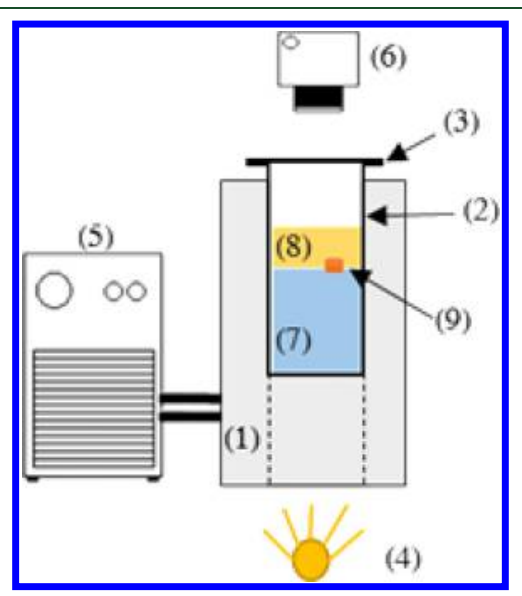

Figure 1. Schematic diagram of the experimental setup at atmospheric pressure: (1) metal jacketed vessel; (2) glass tube (diameter $28 \mathrm{~mm}$ ); (3) glass cap; (4) LED light table; (5) chiller; (6) binocular magnifier with camera; (7) aqueous solution; (8) cyclopentane; (9) hydrate crystal seeds. the target temperature, crystallization was triggered by seeding the system with a few small CP-hydrate crystals that had been formed in advance. Note that for some experiments (not reported in this work) we induced hydrate formation using the memory effect (after hydrate melting) ${ }^{23-25}$ We observed the same hydrate morphology as when performing seeding with small crystals. All of the microscopic experiments presented in this work were conducted with a surfactant concentration of $1 \mathrm{wt} \%$.

On the basis of the snapshots of the hydrate growth at the planar water/CP interface, the lateral hydrate growth rate, noted $v$, was evaluated by measuring the position of the hydrate crystallization front using the same method as described by Delroisse et al. (2017). ${ }^{17}$ The growth rate was evaluated only for systems where the hydrates were growing in a continuous layer at the water/CP interface.

The wettability of the hydrate crystals was determined by placing a ( 1 ${ }^{\circ} \mathrm{C}$ ) small cold drop of the aqueous solution on the hydrate layer formed at the water/CP interface. If the drop spread, the hydrate was water wettable, but if it remained spherical, the hydrate was $\mathrm{CP}$ wettable.

$\mathrm{CH}_{4} / \mathrm{C}_{3} \mathrm{H}_{8}$ Hydrates. Hydrate formation in the presence of the $\mathrm{CH}_{4} /$ $\mathrm{C}_{3} \mathrm{H}_{8}$ gas mixture was studied in a jacketed high pressure cell (designed by Top Industrie, France) made of 316 stainless steel with an internal volume of $17 \mathrm{~cm}^{3}$. A schematic diagram of the experimental setup is given in Figure 2. The cell has two sapphire windows of $18 \mathrm{~mm}$ in

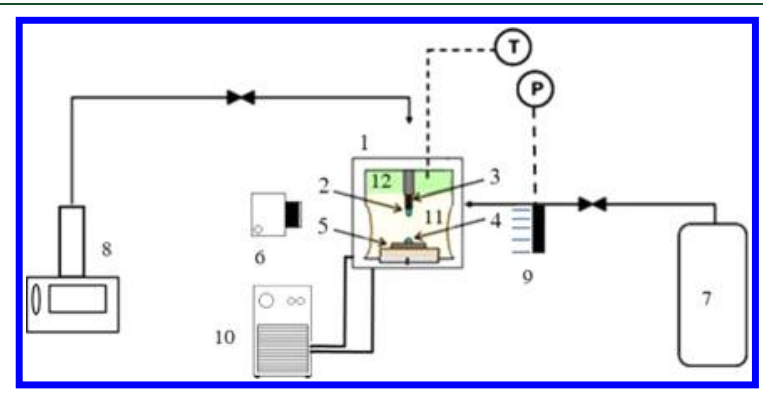

Figure 2. Schematic diagram of the experimental setup at high pressure: (1) high pressure cell; (2) pendant drop; (3) capillary; (4) deposited drop; (5) metal tray; (6) binocular magnifier with camera linked to a computer; (7) gas storage tank; (8) Isco pump; (9) LED light table; (10) chiller; (11) $n$ octane; (12) $\mathrm{CH}_{4} / \mathrm{C}_{3} \mathrm{H}_{8}$ gas mixture.

diameter and comprises a horizontal tray and a vertically movable capillary, which is connected to a syringe pump (Isco 100DM) used to form a drop of the aqueous phase at the tip of the capillary. The latter can be moved down so that the water drop can be placed on the tray. The cell is connected to a gas storage vessel and a pressure sensor. A chiller (Huber minichiller) regulates the cell temperature, measured with a Pt100 probe with an accuracy of $\pm 0.1^{\circ} \mathrm{C}$. The optical and imaging system used to view the inside of the cell is composed of an LED ring light (from Advanced Illumination) and a binocular magnifier (Wild Heerbrugg) fitted with a CCD camera (IDS UI124xSE C) connected to a computer.

In a typical experiment, the cell was first filled with $9 \mathrm{~cm}^{3}$ of $n \mathrm{C} 8$ using a glass syringe, at atmospheric pressure and ambient temperature, before being closed. The system was cooled to $5.4{ }^{\circ} \mathrm{C}$, and the cell was then rapidly loaded with the $\mathrm{CH}_{4} / \mathrm{C}_{3} \mathrm{H}_{8}$ gas mixture at $70 \mathrm{bar}$. In these conditions, the subcooling was about $10{ }^{\circ} \mathrm{C}$ (evaluated using the CSMGem software program ${ }^{1}$ ). The hydrate crystallization was triggered drawing on the "memory effect" of the water after an ice formation/dissociation cycle. ${ }^{26}$ To achieve this, the surfactant solution in the capillary tube connected to the high pressure cell and the syringe pump was frozen by pouring liquid nitrogen on it. Once the liquid was frozen, the pressure in the syringe pump was increased by a few bars to create an overpressure on the ice plug. As soon as the ice plug had melted (indicated by a pressure decrease in the syringe pump), the pump was used to slowly push the cold water to form a drop at the tip of the capillary. The drop was then deposited on the horizontal tray. Note that for these experiments the tray was covered with Teflon tape to prevent the drop from spreading and keep it as spherical as possible. 
Hydrate formation was usually observed to occur a few seconds after the drop was deposited. Snapshots of the hydrate crystallization and growth were taken and recorded at regular intervals. The experiments were performed with a surfactant concentration of $0.1 \mathrm{wt} \%$, because the interfacial tension between the surfactant solution and the $n \mathrm{C} 8$ was too low when concentrations were higher, making it difficult to control the formation of the drop and to deposit it on the tray (see Supporting Information $\mathrm{C}$ ).

2.3. Evaluation of Antiagglomeration Performance. The experimental apparatus used is detailed in Figure 3. The stirred tank

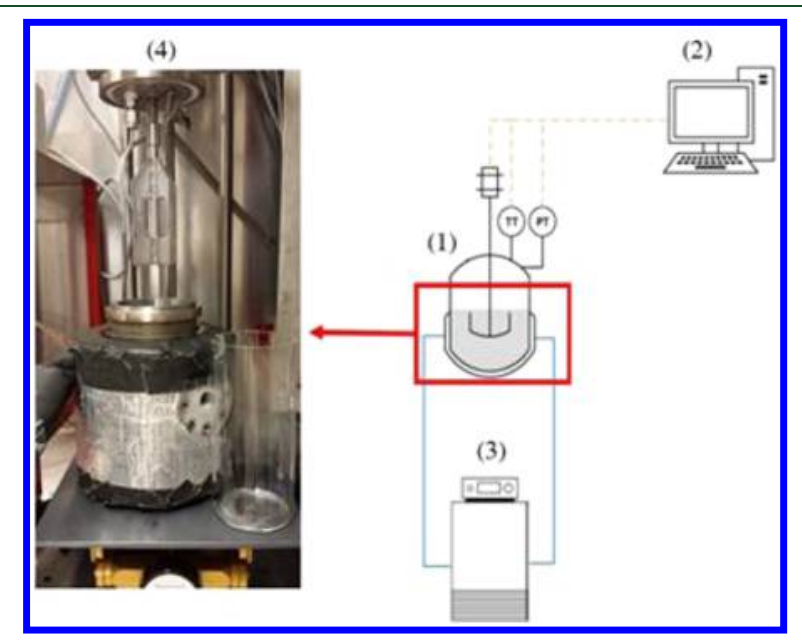

Figure 3. Schematic diagram of the experimental setup: (1) high pressure reactor; (2) computer control; (3) chiller; (4) picture of the reactor with the agitator and the cylindrical glass vessel.

reactor (designed by Parr Instrument Co.) is a jacketed, high pressure reactor made of 316 stainless steel with an internal volume of $360 \pm 3$ $\mathrm{cm}^{3}$. For agitation, the reactor is equipped with a homemade flat blade turbine (with four blades) driven by an ac motor, which is able to maintain a constant rotational speed throughout the experiment. A Pt100 probe (accurate to within $\pm 0.2{ }^{\circ} \mathrm{C}$ ) is used to measure the temperature in the liquid phase. The temperature in the reactor is maintained at the required value-with a stability of $\pm 0.2{ }^{\circ} \mathrm{C}$ - by continuous forced circulation of a water-propylene glycol mixture in the reactor jacket using a thermostatic bath (Polystat 37, Fischer Scientific). A torque meter (provided by Kistler, model 4503) is placed on the stirring shaft and allows the agitator torque to be measured up to $2 \mathrm{~N} \cdot \mathrm{m}$ with an accuracy of $0.2 \%$. Note that the agitation motor can deliver a maximum torque of $0.7 \mathrm{~N} \cdot \mathrm{m}$. The reactor contains an extractable cylindrical glass vessel of $300 \mathrm{~cm}^{3}$. The inner surface of this glass vessel is hydrophobized using $1 \mathrm{H}, 1 \mathrm{H}, 2 \mathrm{H}, 2 \mathrm{H}$ perfluorodecyltri chlorosilane to limit the adhesion of hydrate particles on its surface during the crystallization.

CP Hydrates. The cylindrical glass vessel was filled with $45 \mathrm{~cm}^{3}$ of pure water or surfactant solution with $1 \mathrm{wt} \%$ DA 50 and with $105 \mathrm{~cm}^{3}$ of CP. These proportions correspond to a water: $\mathrm{CP}$ ratio of $30: 70(\mathrm{v} / \mathrm{v}$ $\%$ ). The agitation was set to $200 \mathrm{rpm}$, allowing good homogenization of the phases, and the system was cooled to $1{ }^{\circ} \mathrm{C}$. Once the target temperature was reached and the system temperature stabilized, agitation was stopped and the reactor briefly opened so that the system could be seeded with a few $\mathrm{CP}$-hydrate crystals formed previously. The reactor was then shut again, and agitation was restarted. Because hydrate crystallization is an exothermic reaction, the onset of the hydrate formation was detected owing to an increase in the reactor temperature and the end of the reaction was identified through a decrease in the reactor temperature (as heat is no longer released by the hydrate formation). When the reactor temperature reached the target temperature again, the experiments were stopped and the reactor opened to collect (whenever possible) samples of the oil phase and of the hydrate particles. The oil phase was analyzed by gas chromatog raphy to determine the water to hydrate conversion (as detailed in the next section Determination of the Water to Hydrate Conversion), and the hydrate particles were observed by microscopy to determine their shape, diameter, agglomeration state, and wettability. The microscopic observations were performed using the experimental setup shown in Figure 1 based on the following protocol: (i) the setup was first cooled to $0{ }^{\circ} \mathrm{C}$; (ii) cold $\mathrm{CP}$ (stored at $-10^{\circ} \mathrm{C}$ ) was then loaded into the glass tube; and (iii) the collected sample was quickly incorporated into the CP. Snapshots of the hydrate particles immersed in the CP were taken. The mean value of the particle diameter was evaluated by measuring the diameter of at least 30 particles.

$\mathrm{CH}_{4} / \mathrm{C}_{3} \mathrm{H}_{8}$ Hydrates. The cylindrical glass vessel was filled with 36 $\mathrm{cm}^{3}$ of pure water or surfactant solution (at $1 \mathrm{wt} \% \mathrm{DA} 50$ ) and completed with $84 \mathrm{~cm}^{3}$ of $n \mathrm{C} 8$ to obtain a water:oil ratio of 30:70 (v:v $\%)$. The reactor was closed, connected to the gas storage tank, and pressurized with the $\mathrm{CH}_{4} / \mathrm{C}_{3} \mathrm{H}_{8}$ gas mixture to an equilibrium pressure of $70 \pm 1$ bar under agitation $(200 \mathrm{rpm})$ at $25^{\circ} \mathrm{C}$. A typical experiment took place in two stages. In the first stage, the hydrate formation was forced by rapidly reducing the system temperature to $2{ }^{\circ} \mathrm{C}$ (which corresponds to a subcooling of about $17^{\circ} \mathrm{C}$ ). Once the hydrate had developed, it was decomposed by raising the temperature at a rate of 2 ${ }^{\circ} \mathrm{C} / \mathrm{h}$ to $25{ }^{\circ} \mathrm{C}$ (about $6{ }^{\circ} \mathrm{C}$ above the hydrate equilibrium temperature). The second stage consisted in using the "memory effect" of water that had previously undergone hydrate formation and decomposition to favor hydrate crystallization. For that purpose, the system was kept under agitation for $2 \mathrm{~h}$ at $25^{\circ} \mathrm{C}$. The agitation was then stopped, and the system was cooled to $10^{\circ} \mathrm{C}$ at a rate of $20^{\circ} \mathrm{C} / \mathrm{h}$ (point $\mathrm{A}$ to $\mathrm{B}$ in Figure 4 ). When the system temperature and pressure were

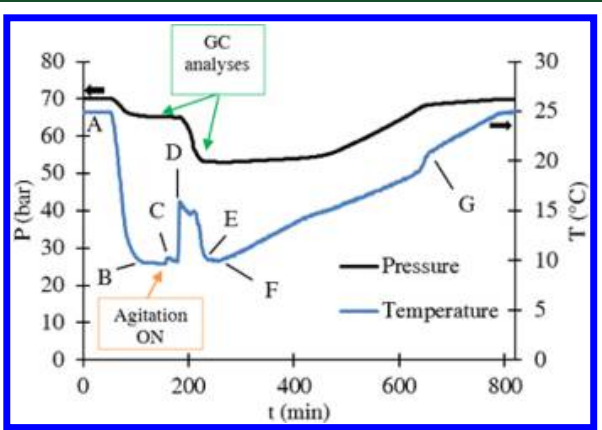

Figure 4. Typical diagram of the system pressure $(P)$ and temperature $(T)$ versus time $(t)$ obtained for the hydrate formation experiments. System: $\mathrm{CH}_{4} / \mathrm{C}_{3} \mathrm{H}_{8}$ gas mixture/ $n \mathrm{C} 8 /$ surfactant solution (1 wt \% DA 50).

stable, agitation was resumed (200 rpm, point C). Hydrate crystallization was detected owing to an increase in the system temperature (due to the exothermicity of the reaction) and a decrease in the system pressure due to gas being consumed by the forming hydrate phase (point D). Gas chromatography (GC) analyses of the gas phase were performed before and after the hydrate formation (points $\mathrm{C}$ and $\mathrm{E}$ ) in order to determine the $\mathrm{CH}_{4}: \mathrm{C}_{3} \mathrm{H}_{8}$ mole ratio. The hydrate was then dissociated by heating the system to $25^{\circ} \mathrm{C}$ at a rate of $2{ }^{\circ} \mathrm{C} / \mathrm{h}$ (points $\mathrm{F}$ to $\mathrm{G}$ ). The variation in the agitator torque measured during the hydrate formation (between points $\mathrm{C}$ and $\mathrm{F}$ ) was used to quantify the degree of agglomeration of the system.

Figure 5 shows the reactor pressure versus temperature curve (also called hysteresis curve) for the hydrate formation experiment shown in Figure 4. The equilibrium curves (calculated using the CSMGem software program ${ }^{1}$ ) for the sII-hydrates formed with the $\mathrm{CH}_{4} / \mathrm{C}_{3} \mathrm{H}_{8}$ $(84 / 16 \mathrm{~mol} / \mathrm{mol} \%)$ gas mixture and for the sI-hydrate formed with pure $\mathrm{CH}_{4}$ are also plotted in this figure. We can see that the hydrates formed outside of the $\mathrm{CH}_{4}$ hydrate stability domain, proving that only sII-hydrates developed during the experiments.

2.4. Determination of the Water-to-Hydrate Conversion. $C P$ Hydrates. The water to hydrate conversion was evaluated by determining, by gas chromatography (GC), the variation of the concentration of $n \mathrm{C} 12$ used as a chemical marker in the CP phase. $n$ $\mathrm{C} 12$ is not soluble in water and does not form gas hydrates. It was used 


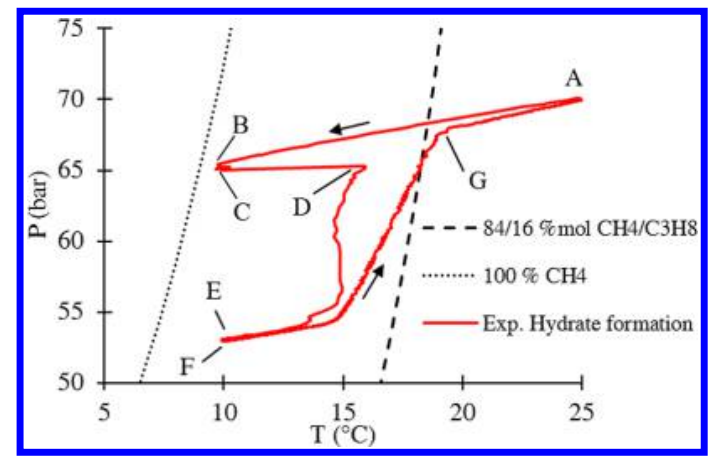

Figure 5. System pressure $(P)$ versus system temperature $(T)$ for the hydrate formation experiment shown in Figure 4. Equilibrium curves of the gas hydrates (calculated with the CSMGem software program) formed with pure $\mathrm{CH}_{4}$ and with the $\mathrm{CH}_{4} / \mathrm{C}_{3} \mathrm{H}_{8}$ gas mixture are also shown.

at a sufficiently low concentration in the $\mathrm{CP}$ phase (2 wt \%) to prevent a significant shift of the $\mathrm{CP}$-hydrate equilibrium temperature. This temperature was measured at $T_{\mathrm{eq}}=7.1 \pm 0.2{ }^{\circ} \mathrm{C}$ in the presence of $2 \mathrm{wt}$ $\%$ of $n \mathrm{C} 12$ instead of $7.2 \pm 0.2{ }^{\circ} \mathrm{C}$ without $n \mathrm{C} 12$, as detailed in the following section Measurement of the Hydrate Equilibrium Temper ature. During hydrate formation, the $\mathrm{CP}$ molecules were consumed and the $n \mathrm{C} 12$ molecules therefore concentrated in the oil phase. Analysis of a sample of the remaining oil phase collected at the end of the experiment helped determine its $n \mathrm{C} 12$ content. Each sample was analyzed 6 times, and the uncertainty was determined from the standard deviation calculated from the 6 values obtained. The molar ratio of the water to hydrate conversion was calculated using the following equation

$$
W=\frac{n_{\mathrm{CP}} \cdot\left(1-\frac{C_{\mathrm{C} 12}^{\mathrm{i}}}{C_{\mathrm{C} 12}^{\mathrm{f}}}\right) \cdot N_{\mathrm{h}}}{n_{\mathrm{w}}}
$$

where $n_{\mathrm{CP}}$ is the number of moles of $\mathrm{CP}, \mathrm{C}_{\mathrm{C} 12}^{\mathrm{i}}$ and $\mathrm{C}_{\mathrm{C} 12}^{\mathrm{f}}$ are the mass fractions of $n \mathrm{C} 12$ in the CP before and after hydrate formation, $N_{\mathrm{h}}$ is the hydration number $\left(N_{\mathrm{h}}=17\right)$, and $n_{\mathrm{w}}$ is the total number of moles of water.

$\mathrm{CH}_{4} / \mathrm{C}_{3} \mathrm{H}_{8}$ Hydrates. In this case, the water to hydrate conversion (molar basis) was determined from the pressure decrease measured during hydrate formation (i.e., between the $\mathrm{GC}$ analyses of points $\mathrm{C}$ and $E$ in Figures 4 and 5)

$$
W=\frac{\frac{V_{\mathrm{g}}}{R T} \cdot\left(\frac{P_{\mathrm{i}}}{z_{\mathrm{i}}}-\frac{P_{\mathrm{f}}}{z_{\mathrm{f}}}\right) \cdot N_{\mathrm{h}}}{n_{\mathrm{w}}}
$$

where the subscripts $i$ and $f$ refer to the initial and final states, $P$ is the reactor pressure, $T$ is the reactor temperature, $V_{\mathrm{g}}$ is the gas volume in the reactor, $R$ is the gas constant, and $n_{\mathrm{w}}$ is the total number of moles of water. $z_{\mathrm{i}}$ and $z_{\mathrm{f}}$ are the compressibility factors of the gas mixture obtained from the Peng-Robinson equation of state. $N_{\mathrm{h}}$ is the hydration number $\left(N_{\mathrm{h}}=6.0\right)$ calculated by determining the equilibrium temperature value for a system of $\mathrm{CH}_{4} / \mathrm{C}_{3} \mathrm{H}_{8}$, water, and $n \mathrm{C} 8$ at $70 \mathrm{bar}$ and at the same molar fractions as used in the experiments using CSMGem.

The volume fraction $(\Phi)$ of the hydrate phase formed in both hydrate systems ( $\mathrm{CP}$ hydrates and $\mathrm{CH}_{4} / \mathrm{C}_{3} \mathrm{H}_{8}$ hydrates) was calculated from the water conversion

$$
\Phi=\frac{V_{\mathrm{h}} \cdot \vartheta}{V_{\mathrm{h}}+\left(V_{\mathrm{w}}-V_{\mathrm{w}} \cdot W\right)+V_{\mathrm{o}}}
$$

where the subscripts $\mathrm{h}, \mathrm{w}$, and o refer to the hydrates, water, and oil, respectively, and $V$ is the volume. The volume of the hydrate phase $\left(V_{\mathrm{h}}\right.$ $\left.=V_{\mathrm{w}} W \vartheta\right)$ is calculated taking in account the volume expansion between the liquid water and the hydrate (noted $\vartheta$ ) equal to 1.18 for $\mathrm{CP}$ hydrates and 1.13 for $\mathrm{CH}_{4} / \mathrm{C}_{3} \mathrm{H}_{8}$ hydrates (obtained using CSMGem).
2.5. Measurement of the Hydrate Equilibrium Temperature. $C P$ Hydrates. In the present study, we used the equilibrium temperatures of the CP hydrates determined previously by Delroisse et al. (2017). ${ }^{17} T_{\text {eq }}=7.2 \pm 0.2^{\circ} \mathrm{C}$ for the $\mathrm{CP}$ hydrates formed with pure water, and $T_{\text {eq }}=5.5 \pm 0.2{ }^{\circ} \mathrm{C}$ for those formed with 4 wt $\% \mathrm{NaCl}$.

$\mathrm{CH}_{4} / \mathrm{C}_{3} \mathrm{H}_{8}$ Hydrates. The equilibrium pressure $\left(P_{\text {eq }}\right)$ and temper ature $\left(T_{\mathrm{eq}}\right)$, corresponding to the pressure and temperature at which the last hydrate crystal present in the system dissociates, were estimated from the hysteresis curve at the inflection point of the heating curve (point G in Figure 5). The results obtained for the systems studied are summarized in Table 1. The hydrate equilibrium temperature for the

Table 1. Equilibrium Temperature and Pressure $\left(T_{\mathrm{eq}}\right.$ and $\left.P_{\mathrm{eq}}\right)$ for Gas Hydrates without DA 50, with 1 wt \% DA 50, and with 1 wt \% DA 50 and 4 wt \% $\mathrm{NaCl}$

\begin{tabular}{lcll}
\multicolumn{1}{c}{ system } & $\mathrm{NaCl}(\mathrm{wt} \%)$ & $T_{\text {eq }}\left({ }^{\circ} \mathrm{C}\right)$ & $P_{\text {eq }}(\mathrm{bar})$ \\
without DA 50 $\left(\right.$ calculated $\left.^{a}\right)$ & 0 & 18.6 & 67 \\
without DA 50 $($ experimental) & 0 & $18.9 \pm 0.5$ & $67 \pm 1$ \\
1 wt \% DA 50 & 0 & $19.5 \pm 0.5$ & $67 \pm 1$ \\
1 wt \% DA 50 and 4 wt \% NaCl & 4 & $18.4 \pm 0.5$ & $65 \pm 1$ \\
${ }^{a}$ Using the CSMGem software program. & &
\end{tabular}

system without $\mathrm{DA} 50$ and $\mathrm{NaCl}$ at $P_{\mathrm{eq}}=67$ bar calculated using CSMGem is also given in Table 1 . The theoretical $T_{\mathrm{eq}}$ is consistent with the experimental value. We believe that the shift (of about $0.6{ }^{\circ} \mathrm{C}$ ) in the measured hydrate equilibrium temperature observed in the presence of 1 wt \% DA 50 was due to a kinetic effect caused by the high heating rate used $\left(2{ }^{\circ} \mathrm{C} / \mathrm{h}\right)$ to dissociate the hydrate ${ }^{27}$ and the adsorbed DA 50 molecules on the hydrate surface that might slow down hydrate dissociation.

\section{RESULTS AND DISCUSSION}

3.1. Hydrate Morphology. CP Hydrates. All of the microscopic observations were conducted at $\Delta T_{\text {sub }}=6.0 \pm$ $0.5^{\circ} \mathrm{C}$. Figure 6 shows snapshots of the hydrate growth at the

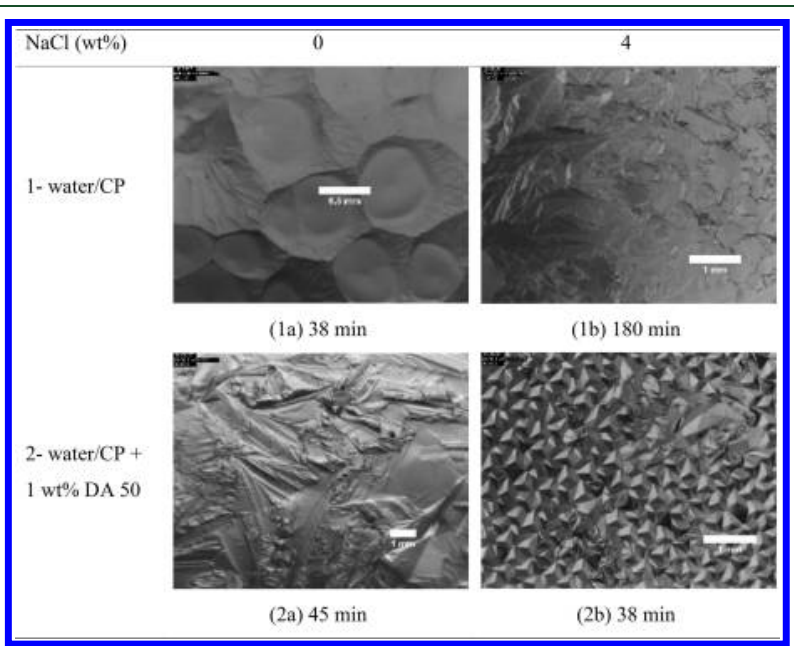

Figure 6. Snapshots showing $\mathrm{CP}$-hydrate morphologies with 0 and 4 wt $\% \mathrm{NaCl}$, without surfactant, and with $1 \mathrm{wt} \% \mathrm{DA} 50$ at a subcooling of $6{ }^{\circ} \mathrm{C}$.

water/CP interface with or without DA 50 and $\mathrm{NaCl}$. The time given was measured from the seeding of the system. Without surfactant (Figure 6.1a and 6.1b) and with $1 \mathrm{wt} \%$ DA 50 without $\mathrm{NaCl}$ (Figure 6.2a), the hydrates formed a shell, composed of smooth and striated plates, at the water/CP interface. The hydrate crystals that developed were water wettable (when a drop of the aqueous solution was deposited on them, it spread). 


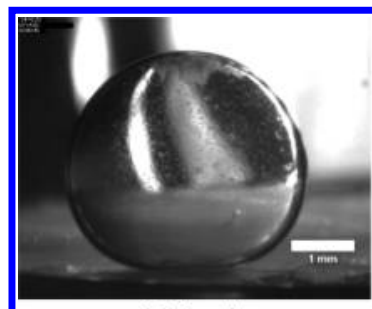

(a) $1 \mathrm{~min}$

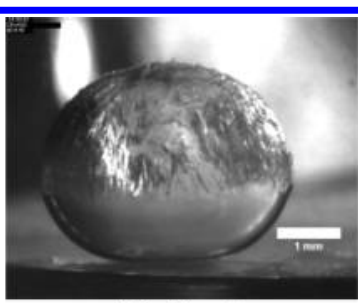

(b) $10 \mathrm{~min}$

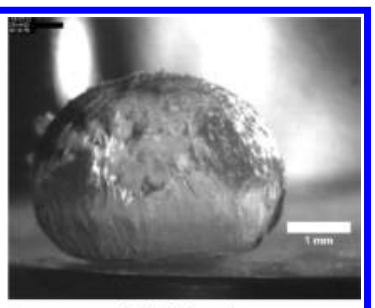

(c) $17 \mathrm{~min}$

Figure 7. Snapshots of gas hydrate formation with $\mathrm{CH}_{4} / \mathrm{C}_{3} \mathrm{H}_{8}$ on a drop of pure water in $n \mathrm{C} 8$ at 66 bar and $T=5.4{ }^{\circ} \mathrm{C}$.

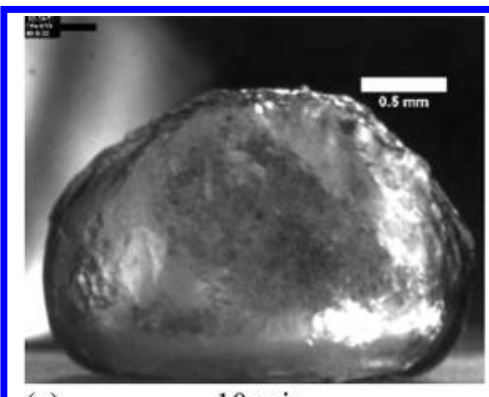

(a) $10 \mathrm{~min}$

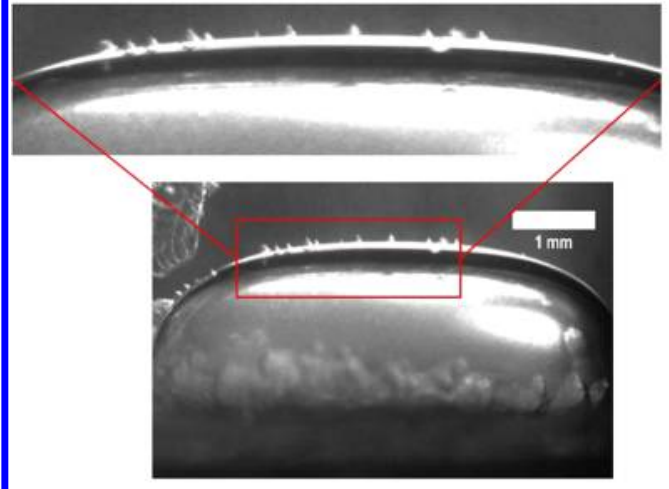

$3 \min$

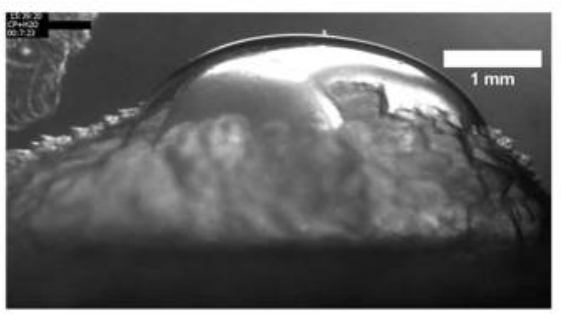

$7 \mathrm{~min}$

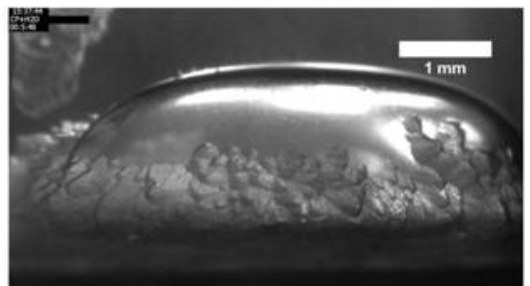

$5 \mathrm{~min}$

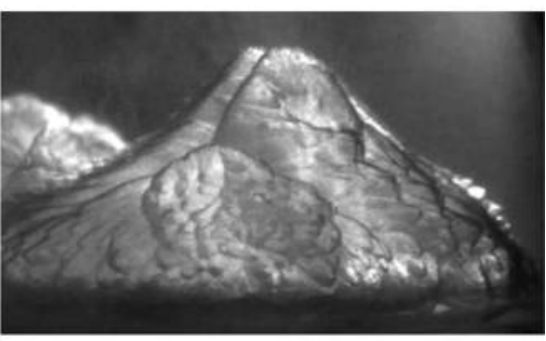

$10 \mathrm{~min}$

(b)

Figure 8. Snapshots of gas hydrate formation with $\mathrm{CH}_{4} / \mathrm{C}_{3} \mathrm{H}_{8}$ on an aqueous drop with 0.1 wt $\%$ DA 50 without (a) or with 4 wt $\% \mathrm{NaCl}$ (b) in $n \mathrm{C} 8$ at 66 bar and a subcooling of $10{ }^{\circ} \mathrm{C}$.

With 1 wt \% DA 50 and 4 wt \% $\mathrm{NaCl}$, a large number of small, individual pyramidal crystals with the vertex pointing to the $\mathrm{CP}$ phase formed at the water/CP interface (Figure 6.2b). These crystals were oil wettable (when a drop of the aqueous solution was deposited on them, it did not spread), and their lateral size was about $300 \mu \mathrm{m}$. Once the water/CP interface was totally covered, the hydrates stopped growing. Note that the same observations were made with 0.1 wt \% DA 50 and 4 wt $\% \mathrm{NaCl}$. All of these results are in perfect agreement with those described by Delroisse et al. (2017) for the same systems. ${ }^{17}$
For the systems with $1 \mathrm{wt} \%$ DA 50, hydrate morphology experiments were also performed with oil phases composed of a $50 / 50$ vol \% mixture of CP and $n$ C8 or $n$ C12 (alkanes which do not form hydrates). The results of these hydrate morphology experiments are presented in Figure S2 of Supporting Information D. In short, adding the alkanes significantly reduced the hydrate growth rate (see Table S3). This observation could be correlated with lower mass transfer kinetics of the CP molecules from the oil phase to the hydrate formation front (compared to pure CP), directly related to the concentration of 


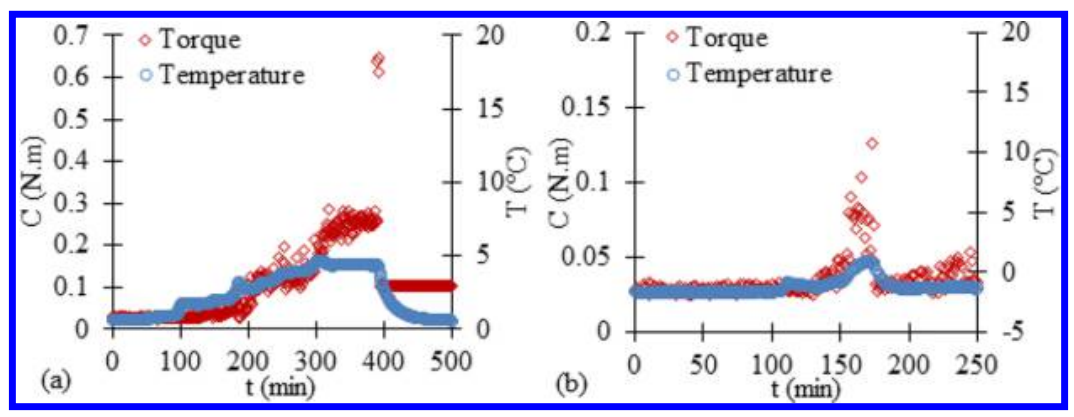

Figure 9. Torque $(C)$ and temperature $(T)$ versus time $(t)$ during the formation of $\mathrm{CP}$ hydrates without surfactant and $\mathrm{NaCl}(\mathrm{a})$ and with $\mathrm{NaCl}(\mathrm{b})$ at a subcooling of $6^{\circ} \mathrm{C}$.

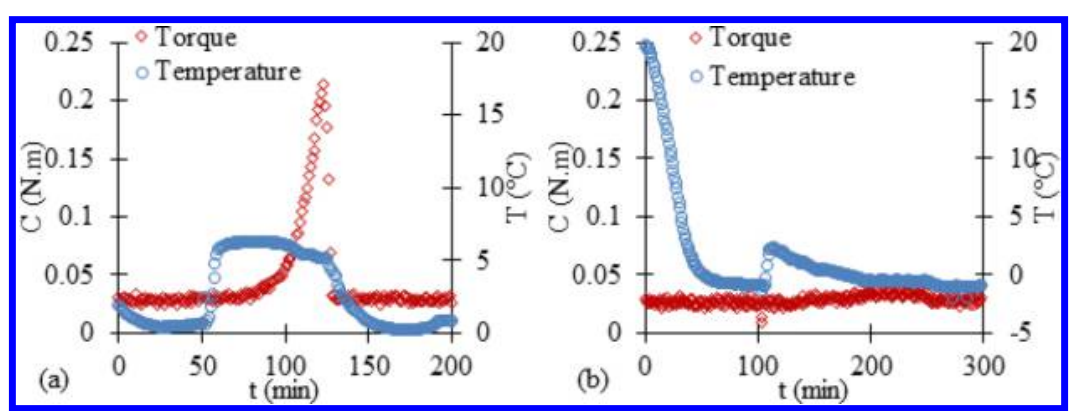

Figure 10. Torque $(C)$ and temperature $(T)$ versus time $(t)$ during the formation of $\mathrm{CP}$ hydrates with $1 \mathrm{wt} \% \mathrm{DA} 50$, without $(\mathrm{a})$ or with $\mathrm{NaCl}(\mathrm{b})$ at a subcooling of $6^{\circ} \mathrm{C}$.

$\mathrm{CP}$ in the oil phase (as $\mathrm{CP}$ is diluted with $n \mathrm{C} 8$ or $n \mathrm{C} 12$ in this case). For example, the lateral hydrate growth rate $(v)$ for the systems without $\mathrm{NaCl}$ in the surfactant solution was three times slower in the presence of $n \mathrm{C} 8(v=0.033 \pm 0.002 \mathrm{~mm} / \mathrm{min})$ or $n \mathrm{C} 12(v=0.032 \pm 0.003 \mathrm{~mm} / \mathrm{min})$ than in an oil phase made up of $100 \% \mathrm{CP}(v=0.11 \pm 0.02 \mathrm{~mm} / \mathrm{min})$. However, the presence of $n \mathrm{C} 8$ or $n \mathrm{C} 12$ in the oil phase had no significant effect on the hydrate morphology. In contrast, with $4 \mathrm{wt} \% \mathrm{NaCl}$ in the surfactant solution, both plate and pyramidal hydrate crystals were observed (instead of only pyramidal crystals when the oil phase was pure CP). The wettability of the hydrates formed was similar to the result obtained for the system with pure $\mathrm{CP}$ as the oil phase.

$\mathrm{CH}_{4} / \mathrm{C}_{3} \mathrm{H}_{8}$ Hydrates. All of the microscopic observations were conducted at $\Delta T_{\text {sub }}=10.0 \pm 0.5{ }^{\circ} \mathrm{C}$ (calculated using $\mathrm{CSMGem}^{1}$ ). Figures 7 and 8 show snapshots of hydrates forming on a sessile aqueous drop (pure water (Figure 7) and a surfactant solution (Figure 8)) immersed in $n \mathrm{C} 8$. The gas phase, which is above $n \mathrm{C} 8$, cannot be seen in these images. Without surfactant and with 0 or 4 wt $\% \mathrm{NaCl}$, a hydrate shell gradually covered the drop surface from top to bottom. An example of the shell formation is presented in Figure 7 for the pure system (Figures $7 \mathrm{a}-\mathrm{c}$ ).

With 0.1 wt \% DA 50, the same hydrate formation pattern as for the system without surfactant was observed, i.e., a hydrate shell formed and progressively covered the drop from top to bottom (see Figure $8 \mathrm{a}$ ). With 0.1 wt $\%$ DA 50 and 4 wt $\% \mathrm{NaCl}$, the hydrate formation pattern changed drastically. In this case, a multitude of pyramidal crystals appeared at the top of the drop (Figure 8b). The vertex of the pyramids pointed to the $n \mathrm{C} 8$ phase, suggesting the crystals were oil wettable. They moved down along the water $/ n \mathrm{C} 8$ interface before accumulating at the bottom of the drop, where they grew in larger quantities. As the amount of hydrates increased, the accumulation of hydrates covered the remaining liquid part of the drop (Figure $8 \mathrm{~b}$ and $8 \mathrm{c}$ ).
The drop seemed to be totally converted into hydrates in about $10 \mathrm{~min}$.

One can see clear similarities in the growth and morphology of the hydrate crystals in both hydrate systems $\left(\mathrm{CP}\right.$ and $\mathrm{CH}_{4} /$ $\mathrm{C}_{3} \mathrm{H}_{8}$ ). In fact, with or without DA 50 and without $\mathrm{NaCl}$, the water/oil interface was progressively covered by a hydrate shell. In the presence of $\mathrm{DA} 50$ and 4 wt $\% \mathrm{NaCl}$, individual pyramidal crystals, with their vertex pointing to the oil phase, formed at the interface. Because the $\mathrm{CP}$-hydrate pyramidal crystals that formed at these concentrations of DA 50 and $\mathrm{NaCl}$ were oil wettable, it is consequently reasonable to assume that those formed with $\mathrm{CH}_{4} / \mathrm{C}_{3} \mathrm{H}_{8}$ hydrates are also oil wettable.

3.2. Antiagglomeration Performance of DA 50. Observation of hydrate formation at the water/oil interface revealed significant changes in the formation pattern, morphol ogy, and wettability of the hydrate crystals when $\mathrm{NaCl}$ was added to the DA 50 solution. To find out if these changes might have an effect on hydrate agglomeration, we measured the agitator torque during hydrate formation in the agitated batch reactor for both hydrate systems.

$C P$ Hydrates. Figure 9a shows the variation in the torque $(C)$ and temperature $(T)$ versus time $(t)$ for a pure water/CP system for a period ranging from $100 \mathrm{~min}$ before the onset of the hydrate crystallization (detected by a significant increase in the system temperature) to $100 \mathrm{~min}$ after the end of the hydrate formation. Once the hydrates started growing, the torque progressively increased to $0.3 \mathrm{~N} \cdot \mathrm{m}$ until the agitator (at around $0.65 \mathrm{~N} \cdot \mathrm{m}$ ) seized up at $400 \mathrm{~min}$. This sudden blockage caused the agitator to disconnect from the motor, and the torque dropped to a constant value of about $0.1 \mathrm{~N} \cdot \mathrm{m}$. This value was above the initial baseline $(\sim 0.025 \mathrm{~N} \cdot \mathrm{m})$ because the hydrates agglomerated around the agitator still maintained a residual torsional strength on the stirring shaft. We opened the reactor and saw that the system was composed of a hydrate plug filling the reactor over the entire height of the agitator (a snapshot of 
the hydrate plug is presented in Supporting Information E), making the agitator and the glass tube interdependent. Due to the lack of supernatant $\mathrm{CP}$, we were unable to determine the water to hydrate conversion. The torque rise observed soon after the beginning of the hydrate growth reflected an increase in the viscosity of the system caused by the formation and agglomeration of the hydrate particles. Agglomeration could be explained by the formation of capillary bridges between adjacent wet hydrate particles. ${ }^{28}$

With 4 wt \% $\mathrm{NaCl}$ (Figure $9 \mathrm{~b}$ ), the torque rapidly increased to $0.13 \mathrm{~N} \cdot \mathrm{m}$ without the agitator seizing up before dropping to the baseline and fluctuating around it. At the end of the experiment, we opened the reactor and saw that hydrate agglomerates were stuck to both the agitator and the inner wall of the glass vessel. The collision of these agglomerates and with the reactor interns (e.g., temperature probe) during agitation caused the erratic torque signal profile (i.e., presence of torque spikes) observed at the end of the experiment. The water to hydrate conversion was not determined because no free CP was visible. The brutal drop in the torque from $0.13 \mathrm{~N} \cdot \mathrm{m}$ to the baseline was probably caused by large hydrate agglomerates suddenly breaking into smaller ones, which have a lower impact on fluid circulation in the reactor.

The torque and temperature as a function of time measured for the system with 1 wt \% DA 50 are shown in Figure 10. The reproducibility of the trends observed was verified (see Figure S5 in Supporting Information F).

Without $\mathrm{NaCl}$, the torque started increasing about $45 \mathrm{~min}$ after the beginning of crystallization and reached $0.22 \mathrm{~N} \cdot \mathrm{m}$ before decreasing rapidly to attain the baseline (Figure 10a). At the end of the experiment, we opened the reactor and saw a large number of hydrate particles dispersed in the CP. The GC analysis of the supernatant $\mathrm{CP}$ phase revealed that all of the water present in the system had been converted into hydrates (Table 2). The agglomerated hydrate particles had a mean

Table 2. Water to Hydrate Conversion $(W)$, Hydrate Volume Fraction $(\boldsymbol{\Phi})$, and Particle Diameter for the Systems with DA 50 and without and with $4 \mathrm{wt} \% \mathrm{NaCl}$ at a Subcooling of $6^{\circ} \mathrm{C}$

\begin{tabular}{ccccc} 
& & \multicolumn{2}{c}{$\mathrm{CP}$ hydrate } & \\
\cline { 3 - 4 } system & $\begin{array}{c}\mathrm{NaCl} \\
(\text { wt \%) }\end{array}$ & $W(\mathrm{~mol} \%)$ & $\Phi($ vol \%) & $\begin{array}{c}\text { particle diameter } \\
(\mu \mathrm{m})\end{array}$ \\
1 wt \% DA 50 & 0 & $100 \pm 8$ & $36 \pm 3$ & $660 \pm 120$ \\
1 wt \% DA 50 & 4 & $72 \pm 6$ & $26 \pm 4$ & $70 \pm 15$
\end{tabular}

diameter of $660 \pm 120 \mu \mathrm{m}$ (Figure 11). A zoomed in view of a particle (Figure 11b) shows that it is composed of several small pieces of hydrates welded together. A drop of a cold aqueous solution of 1 wt \% DA 50 deposited on the particles made them wet (Figure 11c), demonstrating that they were water wettable.

In an attempt to obtain more information on the system responsible for the torque variations during the experiment, we conducted two complementary experiments on the system with $1 \mathrm{wt} \%$ DA 50. In the first, we stopped the agitation and opened the reactor every $15 \mathrm{~min}$ to take snapshots of the system (see Figure 12). In Figure 12, the torque vs time curve can be divided into three parts. The first (marked 1) corresponds to the water/ CP/DA 50 system before seeding. Here, a homogeneous emulsion (of the o/w type according to the Bancroft rule) was formed by agitation. The second part (marked 2 ) corresponds to the stage where the torque increased due to the formation of hydrates. In this part, the reactor was opened six times. The first two times the system consisted of a milky dispersion of hydrate particles and doubtless of CP droplets in the aqueous phase (due to the initial o/w emulsion type). To the naked eye, it was moderately viscous. From the third opening, the system became a jelly like material. This change was caused by the increasing amount of dispersed phase (CP and hydrate particles) in the water phase. The last part (marked 3) corresponds to the drop in torque. The first time the reactor was opened after the maximum torque value was reached we observed a small amount of supernatant CP phase and a large number of hydrate particles forming clusters. The volume of the supernatant CP phase increased until the torque reached the baseline. Here, the system was composed of hydrate particles dispersed in a continuous CP phase (top right hand picture in Figure 12).

The second experiment consisted in measuring the conductivity $(\sigma)$ of the system as a function of time to determine whether the sudden decrease in the torque signal was caused by the inversion of the continuous phase from water to CP. Note that in this experiment 0.25 wt $\% \mathrm{NaCl}$ was added to the deionized water so that the water and $\mathrm{CP}$ conductivities would be clearly distinguishable. The values of $\sigma$ vs time are plotted in Figure 13. The point at $t=0 \mathrm{~min}$ corresponds to the seeding of the system. Before the seeding, the emulsion formed by agitation had a conductivity of $1060 \mu \mathrm{S} / \mathrm{cm}$, proof that it was of the o/w type. After the seeding, the torque progressively rose while $\sigma$ decreased due to the increase in the volume fraction of the dispersed phase as hydrate particles were forming. As already observed in the first experiment, the initial emulsion changed into a jelly like dispersion. Because the conductivity of this dispersion was still high $(300-1000 \mu \mathrm{S} / \mathrm{cm})$, its external phase

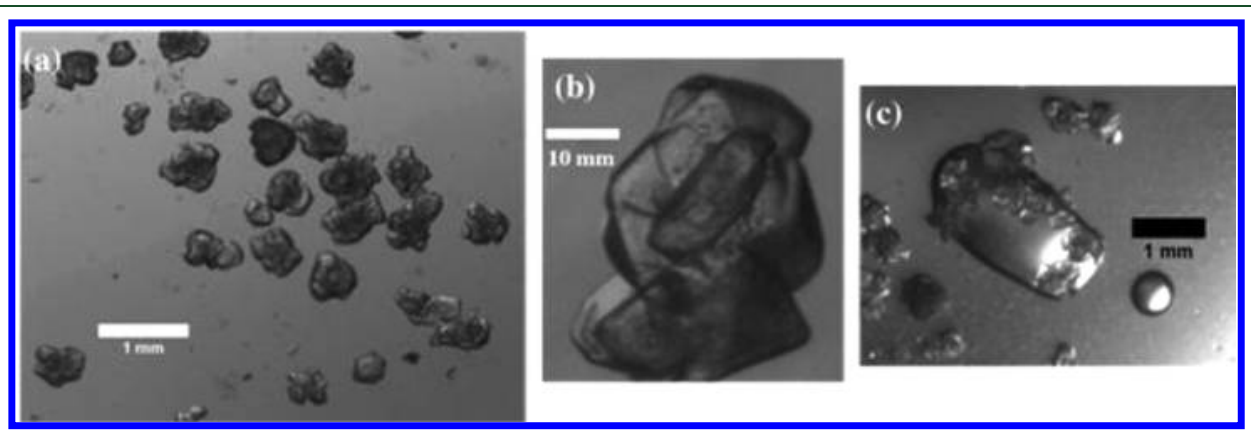

Figure 11. Snapshots of agglomerated hydrate particles at the end of the $\mathrm{CP}$-hydrate formation experiments in the batch reactor with $1 \mathrm{wt} \% \mathrm{DA} 50$ (a), zoomed in view of a hydrate particle composed of small pieces of hydrates welded together (b), and particles wetted by a drop of cold aqueous solution of 1 wt \% DA 50 (c). 


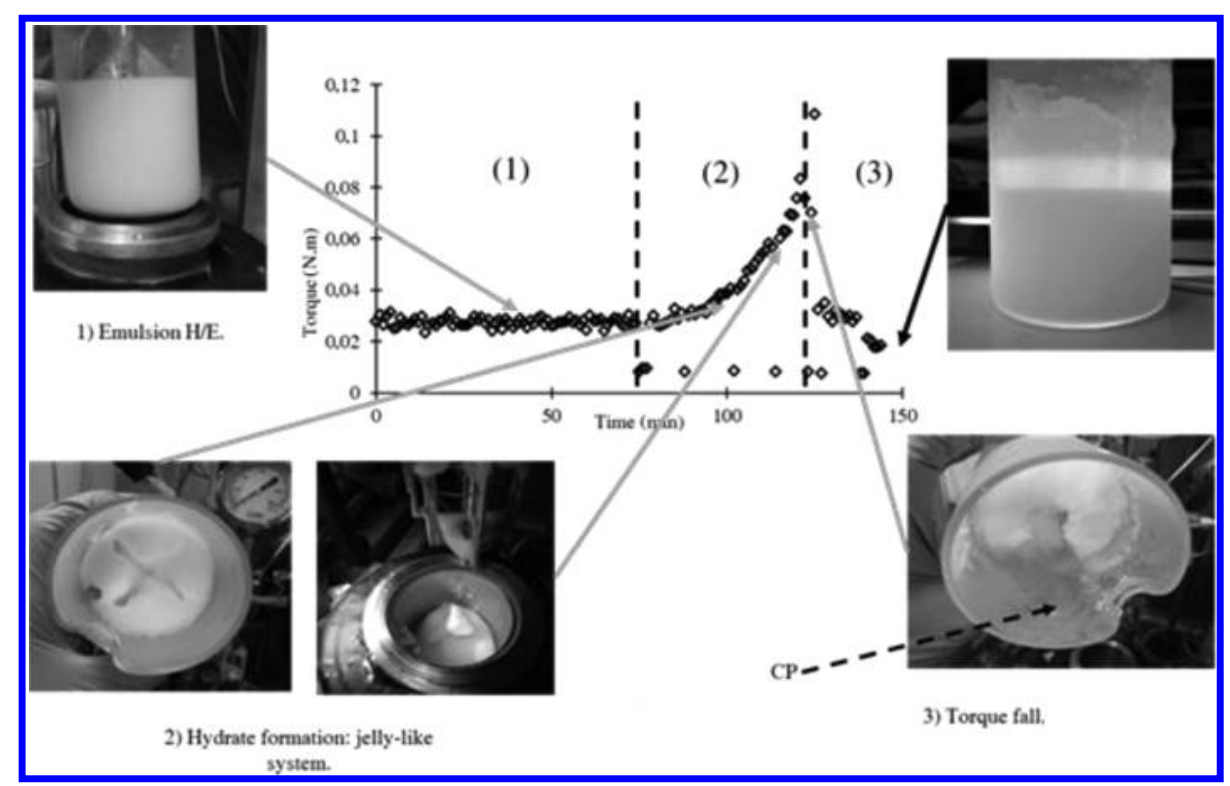

Figure 12. States of the water/CP/hydrate system in the presence of $1 \mathrm{wt} \% \mathrm{DA} 50$ and of the torque as a function of time.

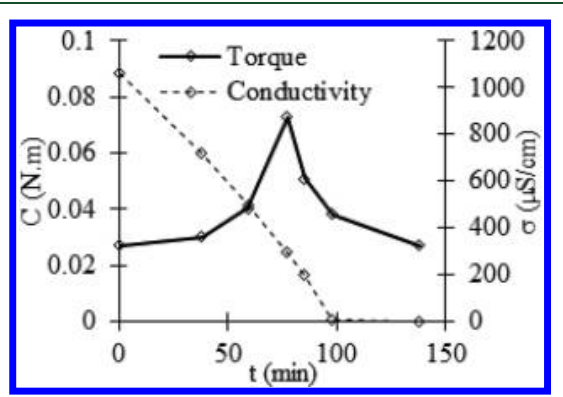

Figure 13. Conductivity $(\sigma)$ and torque $(C)$ versus time $(t)$ measured during hydrate formation with 1 wt $\%$ DA 50 and 0.25 wt \% NaCl.

was, consequently, the aqueous phase. The torque signal began to drop at $t=80 \mathrm{~min}$, while $\sigma$ kept on decreasing until $t=100$ $\mathrm{min}$. As mentioned above, the system released a small amount of the CP phase as soon as the torque decreased. However, as $\sigma$ was not equal to zero, the system was not completely inverted. Here, the system was composed of a sedimented phase, containing a large number of hydrate particles, and a supernatant CP phase. The amount of CP phase released progressively increased as the water was converted into hydrates. At $t=100 \mathrm{~min}$, the zero value of $\sigma$ indicated the CP phase was now the continuous phase. As suggested by the GC analyses of the CP released, all of the water was converted into hydrates. With no more free water available in the system, capillary bridges between the hydrate particles could not form (the hydrate particles were "dry") and their agglomeration was therefore limited.

With 4 wt \% $\mathrm{NaCl}$ (Figure 10b), the torque value remained almost constant at a very low value (i.e., lower than $0.05 \mathrm{~N} \cdot \mathrm{m}$ ) during the hydrate formation and without any blockage of the agitator. Ten hours after hydrate formation, the reactor was opened. We observed that the system was composed of a dispersion of small hydrate particles with a mean diameter of 70 $\pm 15 \mu \mathrm{m}$. When a drop of a cold aqueous solution of $1 \mathrm{wt} \% \mathrm{DA}$ 50 and 4 wt $\% \mathrm{NaCl}$ was deposited on the particles, it did not cover them but was repelled, meaning that the particles were hydrophobic. The water to hydrate conversion was determined to be $72 \pm 6 \mathrm{~mol} \%$, which corresponds to a hydrate fraction of $26 \pm 4 \mathrm{vol} \%$. The presence of unconverted water was due to the presence of $\mathrm{NaCl}$. Although there was still free water in the system, the fact that the particles were hydrophobic prevented the formation of capillary bridges between them, thereby limiting their agglomeration.

To verify that the difference in torque behavior observed between the systems without and with 4 wt \% $\mathrm{NaCl}$ (Figure 10a and $10 \mathrm{~b}$ ) was not caused by the difference in the volume fraction of the hydrate phase (36 vol \% without $\mathrm{NaCl}$ against $26 \mathrm{vol} \%$ with $\mathrm{NaCl}$ ), we conducted a new experiment. We used the required amount of aqueous phase (containing 1 wt \% DA 50 and no salt) to obtain-after total conversion of water into hydrates-the same volume fraction of hydrates as for the system with 1 wt \% DA 50 and 4 wt \% $\mathrm{NaCl}$ (i.e., 26\%). As expected, this system formed a jelly like material (visible to the naked eye) responsible for the torque increase (up to $0.06 \mathrm{~N} \cdot \mathrm{m}$ (see Figure S6 in Supporting Information G)). Then the torque fell rapidly to the baseline as observed in the system with 1 wt \% DA 50 and no salt (Figure 10a), and the final system was composed of hydrate particles dispersed in a continuous CP phase. These observations demonstrated that the difference between the torque behaviors observed without and with 4 wt \% $\mathrm{NaCl}$ was not caused by the difference in the volume fraction of the hydrate phase but by the improved antiagglomeration performance of DA 50 with $\mathrm{NaCl}$.

Antiagglomeration performance experiments were also conducted for the systems with 1 wt $\%$ DA 50 and 0 or 4 wt $\% \mathrm{NaCl}$ and oil phases composed of a 50/50 vol \% mixture of CP and $n \mathrm{C} 8$ or $n \mathrm{C} 12$. Results are presented in Figure S3 in Supporting Information D. Without surfactant, hydrates agglomerated and stuck to the agitator and the glass vessel for both oil mixtures. With $1 \mathrm{wt} \%$ DA 50, the system formed a jelly like material when no salt was present and a flowable hydrate slurry in the presence of $4 \mathrm{wt} \% \mathrm{NaCl}$. These experiments showed that the solution with 1 wt \% DA 50 and 4 wt $\% \mathrm{NaCl}$ effectively prevents hydrate agglomeration for different oil phases.

$\mathrm{CH}_{4} / \mathrm{C}_{3} \mathrm{H}_{8}$ Hydrates. Figure 14 shows the torque, pressure, and temperature variations versus time for the systems without surfactant, with 1 wt \% DA 50, and with 1 wt \% DA 50 and 4 wt \% $\mathrm{NaCl}$ at a subcooling of $9{ }^{\circ} \mathrm{C}$. The final values of the water to 


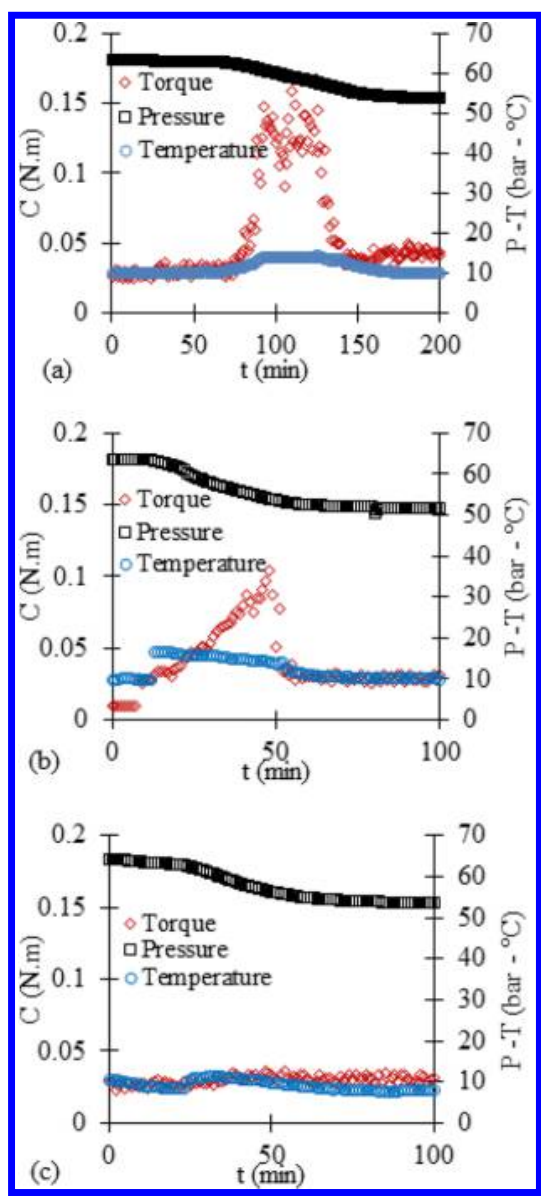

Figure 14. Torque $(C)$, pressure $(P)$, and temperature $(T)$ versus time $(t)$ during the gas hydrate formation without surfactant (a), with $1 \mathrm{wt} \%$ DA 50 without $\mathrm{NaCl}$ (b), and with 1 wt $\%$ DA 50 and 4 wt $\% \mathrm{NaCl}$ (c) at a subcooling of about $9^{\circ} \mathrm{C}$.

hydrate conversion and the hydrate volume fraction are given in Table 3.

Table 3. Water to Hydrate Conversion $(W)$ and Hydrate Volume Fraction $(\Phi)$ in the Presence of DA 50 without and with 4 wt $\% \mathrm{NaCl}$ at a Subcooling of $9^{\circ} \mathrm{C}$

\begin{tabular}{cccc}
\hline system & $\mathrm{NaCl}(\mathrm{wt} \%)$ & $W(\%)$ & $\Phi(\% \mathrm{vol})$ \\
without DA 50 & 0 & $49 \pm 5$ & $17 \pm 2$ \\
1 wt \% DA 50 & 0 & $52 \pm 5$ & $18 \pm 2$ \\
1 wt \% DA 50 & 4 & $42 \pm 4$ & $14 \pm 1$ \\
\hline
\end{tabular}

Without surfactant (Figure 14a), the hydrate crystallization caused the torque to increase to about $0.15 \mathrm{~N} \cdot \mathrm{m}$. The torque then fluctuated around this value before suddenly dropping to the baseline $(0.025 \mathrm{~N} \cdot \mathrm{m})$. Frictions between hydrate agglom erates on the agitator and the glass tube wall might be the reason for the erratic torque signal profile. The rapid drop to the baseline might be due to the hydrate agglomerates breaking into smaller ones. The final hydrate volume fraction was $17 \pm 2$ vol \% (water to hydrate conversion of $49 \pm 5 \mathrm{~mol} \%$ ).

With 1 wt \% DA 50 (Figure 14b), the crystallization induced a progressive increase of the torque signal up to $0.10 \mathrm{~N} \cdot \mathrm{m}$ before it rapidly fell to the baseline. Surprisingly, the final hydrate volume fraction $(18 \pm 2 \mathrm{vol} \%)$ was almost the same as for the system without surfactant $(17 \pm 2$ vol \%). Since the interfacial area between the aqueous and the oil phases should increase in the presence of a surfactant in agitated systems, one might have expected a higher water to hydrate conversion. In fact, hydrate growth seemed to end when the $\mathrm{C}_{3} \mathrm{H}_{8}$ was depleted. For both systems, less than $1 \mathrm{~mol} \%$ of $\mathrm{C}_{3} \mathrm{H}_{8}$ remained in the gas phase at the end of the hydrate formation.

The sudden drop in torque is similar to that observed for CP hydrates with DA 50 (Figure 10a), which was caused by inversion of the continuous phase (from water to $\mathrm{CP}$ ) induced by the very high (nearly complete) water to hydrate conversion. However, in the present case, the conversion was not complete (52 mol \%). In 2011, Moradpour et al. ${ }^{29}$ showed that the emulsion type could change during gas hydrate formation. With $1 \mathrm{wt} \%$ of a quaternary ammonium salt in a system with $60 \mathrm{vol} \%$ of water, the authors observed that inversion of the emulsion type (from o/w to w/o) occurred when the volume fraction of hydrates reached $1-11 \%$ depending on the oil used (crude oils in their case). As already mentioned, the DA 50 promoted the formation of an o/w emulsion for a water/n C8 system (at atmospheric pressure). We assume the same type of emulsion formed in the presence of the gas phase. Consequently, the viscosity of the system initially increased because the volume of the dispersed phases ( $n \mathrm{C} 8$ and hydrates) increased. On the basis of the variation in the reactor pressure, measured between the beginning of hydrate crystallization and the onset of the torque drop, we calculated that the hydrate volume fraction was 16 vol \%. A phase inversion therefore possibly explains the torque signal behavior.

In the presence of $4 \mathrm{wt} \% \mathrm{NaCl}$, the torque remained almost constantly at the baseline as the hydrate was forming (Figure $14 \mathrm{c})$. The hydrate volume fraction $(14 \pm 1 \mathrm{vol} \%)$ was about the same as that for the other systems, for which a large increase in the torque value was observed. Consequently, as already observed for the $\mathrm{CP}$-hydrate systems, the presence of $\mathrm{NaCl}$ greatly improved the antiagglomeration performance of DA 50 for gas hydrates.

3.3. Discussion on the Correlation between the Hydrate Morphology and the Antiagglomeration Performance of the Surfactant. Microscopic observation of the hydrate crystals formed at a quiescent water/oil interface seems to provide valuable information on the capacity of the surfactant used to prevent hydrate agglomeration. Actually, we saw that DA 50 exhibited good antiagglomeration performance only when it induced the formation of individual oil wettable crystals at the quiescent interface. It is particularly interesting to note that the improvement in the antiagglomeration performance of DA 50 induced by the $\mathrm{NaCl}$ coincides with the changes in morphology (from plates to pyramids) and wettability (from water to oil) of the crystals formed. Good antiagglomeration performance of surfactant molecules coupled with the formation of oil wettable crystals is consistent with the results recently published by Brown et al. (2018). ${ }^{30}$

Whether the oil phase was a mixture of $n \mathrm{C} 8 / \mathrm{CP}, n \mathrm{C} 12 / \mathrm{CP}$, or pure $\mathrm{CP}$, the hydrate growth pattern and the morphology of the hydrate crystals formed without or with DA 50 was very similar. Even if some morphological differences were observed when $\mathrm{NaCl}$ was added to the DA 50 solution (a mixture of plate and pyramidal crystals for systems with $n \mathrm{C} 8 / \mathrm{CP}$ or $n \mathrm{C} 12 / \mathrm{CP}$ instead of pyramidal crystals only with pure $\mathrm{CP}$ as the oil phase), the presence of $\mathrm{NaCl}$ drastically improved the antiagglomera tion performance of DA 50. The differences observed in the hydrate morphology might be explained by changes in the physicochemical environment of the surfactant. The presence of alkane chains in the $\mathrm{CP}$ phase and of $\mathrm{NaCl}$ in the aqueous phase 
modified the affinity of the surfactant for both phases ${ }^{3}$ and hence its interactions with the w/o interface and hydrate surface.

It can be noted that the shapes of the $\mathrm{CP}$-hydrate particles formed in the agitated reactor were different from those of the hydrate crystals observed at the quiescent water/CP interface (pyramids for the latter and spherical particles for the former for the systems with $1 \mathrm{wt} \% \mathrm{DA} 50$ and $4 \mathrm{wt} \% \mathrm{NaCl}$ for example). Continuous mixing of the water/CP/hydrate phase, which is conducive to hydrate growth in all directions and causes collisions between the hydrate crystals, is undoubtedly responsible for the difference in the shapes observed.

Finally, the observations (morphology and wettability of the hydrate crystals and the antiagglomeration performance of the surfactant) made with both hydrate systems ( $\mathrm{CP}$ and $\mathrm{CH}_{4}$ / $\mathrm{C}_{3} \mathrm{H}_{8}$ ) appeared consistent, suggesting that $\mathrm{CP}$ hydrates are a good sII-hydrate model. This point is in agreement with conclusions recently given by Abojaladi and Kelland ${ }^{9}$ (2016), namely, that CP hydrates could be a good analog for sII gas hydrates for a first time screening of the antiagglomeration performance of surfactants.

\section{CONCLUSION}

The microscopic observations of hydrate growth at a quiescent water/oil interface showed that adding $\mathrm{NaCl}$ to a DA 50 solution has a significant effect on the morphology and wettability of the hydrate crystals formed. With $0.1-1$ wt \% DA 50 and no salt, the hydrates formed water wettable plates, but by adding 4 wt \% $\mathrm{NaCl}$ to the surfactant solution individual oil wettable pyramidal crystals developed.

The antiagglomeration performance experiments on $\mathrm{CP}$ hydrates showed that the system with 1 wt \% DA 50 went through a jelly like dispersion phase composed of CP and hydrate particles in a small amount of liquid water, a state definitely incompatible with transportation of the system in a pipeline. However, as hydrates continued to form, inversion of the continuous phase occurred (i.e., the CP became the continuous phase) and the torque (and consequently the system viscosity) fell. The dispersed phase represented more than 70 vol \% before the inversion and about 36 vol \% afterward. Due to the high (nearly total) water to hydrate conversion, the system was ultimately composed of "dry" hydrate particles dispersed in the CP phase. The absence of free water prevented the formation of capillary bridges between the particles and thus their agglomeration. As a result, the hydrate slurry formed was flowable. The addition of $\mathrm{NaCl}$ to the $\mathrm{DA} 50$ solution reduced the size of the $\mathrm{CP}$-hydrate particles by a factor of 10 (from about 700 to $70 \mu \mathrm{m}$ ) and made them oil wettable, which improved the antiagglomeration performance of the DA 50 molecules (no torque increase observed during the hydrate formation). Note that good correlations were found between the wettability of the hydrate crystals formed in the agitated reactor and at the quiescent water/CP interface.

In the case of $\mathrm{CH}_{4} / \mathrm{C}_{3} \mathrm{H}_{8}$ hydrates, the same trends were observed. With 1 wt \% DA 50 and no salt, hydrates agglomerated (high torque increase observed), but by adding $4 \mathrm{wt} \% \mathrm{NaCl}$ to the surfactant solution a flowable hydrate slurry formed (no torque increase observed).

Interestingly enough, the addition of 50 vol \% of $n$ C 8 or $n$ $\mathrm{C} 12$ to the CP oil phase had a negligible effect on the morphology and wettability of the $\mathrm{CP}$-hydrate crystals and the antiagglomeration performance of DA 50. It mainly reduced the kinetics of the hydrate formation and the water to hydrate conversion. Therefore, mixing CP with another oil (instead of using pure $\mathrm{CP}$ ) to study $\mathrm{CP}$-hydrate formation makes it possible to keep a certain amount of free water throughout the experiment to better mimic the conditions of gas hydrate formation with pressurized gases.

From the experimental results obtained in this study, it seems possible to infer the following correlation between the morphology of the hydrate crystals observed at the w/o interface and the antiagglomeration performance: the systems that form a hydrate shell at the interface exhibit poor antiagglomeration performance, whereas those that form individual oil wettable crystals achieve good antiagglomeration performance. Consequently, microscopic observation of hydrate formation at a quiescent water/oil interface, and more particularly at a water/CP or water/ $(\mathrm{CP}+$ oil $)$ interface at atmospheric pressure, might be an appropriate solution for obtaining valuable indicators as regards the antiagglomeration capacities of a surfactant. The morphological similarities between the $\mathrm{CP}$-hydrate and $\mathrm{CH}_{4} / \mathrm{C}_{3} \mathrm{H}_{8}$ hydrate crystals in addition to those observed for the antiagglomeration perform ance of DA 50 on both hydrate systems confirm that the CP hydrates are an interesting analog for sII gas hydrates when performing a quick evaluation of antiagglomeration surfactants.

\section{ASSOCIATED CONTENT}

\section{Supporting Information}

The Supporting Information is available free of charge on the ACS Publications website at DOI: 10.1021/acs.energy fuels.8b02980.

Representation of a Noramium DA 50 molecule; description of the study of the emulsion formation and stability in the presence of DA 50 with 0 and 4 wt $\% \mathrm{NaCl}$ for a water:oil ratio of 30:70 (v:v\%); table containing the stability and type of emulsions formed is also presented; experimental protocol used to measure the interfacial tension (IFT) between aqueous solutions (pure water and DA 50 solutions without and with $\mathrm{NaCl}$ ) and $n \mathrm{C} 8$ in the presence of the $\mathrm{CH}_{4} / \mathrm{C}_{3} \mathrm{H}_{8}$ gas mixture at 58 bar and $10{ }^{\circ} \mathrm{C}$; table containing the measured IFT values; description of the $\mathrm{CP}$-hydrate morphology and of the antiagglomeration performance of DA 50 evaluated in the agitated batch reactor in the presence of alkanes $(n \mathrm{C} 8$ or $n \mathrm{C} 12)$; snapshots of the $\mathrm{CP}$-hydrate growth at the water $/(\mathrm{CP}+n \mathrm{C} 8$ or $\mathrm{CP}+n \mathrm{C} 12)$ interface and torque and temperature versus time during the formation of $\mathrm{CP}$ hydrates without surfactant with 1 wt \% DA 50 and 0 or 4 wt $\% \mathrm{NaCl}$ at a subcooling of $6{ }^{\circ} \mathrm{C}$; table summarizing the lateral growth $v$ of the hydrates for these systems at a subcooling of $6{ }^{\circ} \mathrm{C}$; figure showing snapshots of the system state in the batch reactor after a hydrate formation experiment without surfactant; figure comparing the torque $(C)$ and temperature $(T)$ versus time $(t)$ of a formation experiment of $\mathrm{CP}$ hydrates without and with $\mathrm{NaCl}$ and 1 wt \% DA 50 at a subcooling of $6{ }^{\circ} \mathrm{C}$ repeated twice; figure showing $C$ and $T$ versus $t$ during the formation of CP hydrates with 1 wt \% DA 50 at a subcooling of $6{ }^{\circ} \mathrm{C}$ for a final volume fraction of hydrates of $26 \%$ (PDF)

\section{AUTHOR INFORMATION}

\section{Corresponding Author}

*Phone: +33559407682. E mail: christophe.dicharry@univ pau.fr. 
ORCID $\odot$

J.-P. Torré: 0000000157358626

C. Dicharry: 0000000263183989

Notes

The authors declare no competing financial interest.

\section{ACKNOWLEDGMENTS}

The authors are grateful to ARKEMA CECA for the financial support of this work and for supplying of the cationic surfactant. Gilles Barreto (ARKEMA CECA) and Philippe Glénat (TOTAL) are also acknowledged for their valuable scientific input and discussions. The authors thank Joseph Diaz (UPPA) for technical help.

\section{REFERENCES}

(1) Sloan, E. D.; Koh, C. A. Clathrate Hydrates of Natural Gases, 3rd ed.; CRC Press, Taylor \& Francis Group: Boca Raton, 2008.

(2) Kelland, M. A. Production Chemicals for the Oil and Gas Industry:

CRC Press, Taylor \& Francis Group: Boca Raton, 2009.

(3) Zerpa, L. E.; Salager, J. L.; Koh, C. A.; Sloan, E. D.; Sum, A. K. Surface chemistry and gas hydrates in flow assurance. Ind. Eng. Chem. Res. 2011, 50, 188-197.

(4) Huo, Z.; Freer, E.; Lamar, M.; Sannigrahi, B.; Knauss, D. M.; Sloan, E. D. Hydrate plug prevention by anti agglomeration. Chem. Eng. Sci. 2001, 56, 4979-4991.

(5) Zanota, M. L.; Dicharry, C.; Graciaa, A. Hydrate plug prevention by quaternary ammonium salts. Energo Fuels 2005, 19, 584-590.

(6) Sun, M.; Firoozabadi, A. New surfactant for hydrate anti agglomeration in hydrocarbon flowlines and seabed oil capture. $L$ Colloid Interface Sci. 2013, 402, 312-319.

(7) York, J. D.; Firoozabadi, A. Comparing effectiveness of thamnolipid biosurfactant with a quaternary ammonium salt surfactant for hydrate anti agglomeration effect of brine on hydrate anti agglomeration. L.Phvs. Chem. B 2008, 112, 845-851.

(8) Li, X.; Negadi, L.; Firoozabadi, A. Anti agglomeration in cyclopentane hydrates from bio and co surfactants. Eneroy Fuels 2010, 24, 4937-4943.

(9) Abojaladi, N.; Kelland, M. A. Can cyclopentane hydrate formation be used to screen the performance of surfactants as LDHI anti agglomerants at atmospheric pressure? Chem. Eng. Sci. 2016, 152, 746753.

(10) Martinez de Baños, M. L.; Carrier, O.; Bouriat, P.; Broseta, D. Droplet based millifluidics as a new tool to investigate hydrate crystallization: Insights into the memory effect. Chem.Eng. Sci. 2015, $123,564-572$.

(11) Delroisse, H.; Plantier, F.; Marlin, L.; Dicharry, C.; Frouté, L.; André, R; Torré, J. P. Determination of thermophysical properties of cyclopentane hydrate using a stirred calorimetric cell. $L$ Chem. Thermodvn, 2018, 125, 136-141.

(12) Yalkowsky, S. H.; He, Y.; Jain, P. Handbook of Aaueous Solubility Data, 2nd ed.; CRC Press: Boca Raton, FL, 2010; p 158.

(13) Dirdal, E. G.; Arulanantham, C.; Sefidroodi, H.; Kelland, M. A. Can cyclopentane hydrate formation be used to rank the performance of kinetic hydrate inhibitors? Chem. Eng.Sci. 2012, 82, 177-184.

(14) Kishimoto, M.; Iijima, S.; Ohmura, R. Crystal growth of clathrate hydrate at the interface between seawater and hydrophobic guest liquid: effect of elevated salt concentration. Ind.Eng. Chem.Res, 2012, 51, 5224-5229.

(15) Mitarai, M.; Kishimoto, M.; Suh, D.; Ohmura, R. Surfactant effects on the crystal growth of clathrate hydrate at the interface of water and hydrophobic guest liquid. Crust. Growth Des. 2015, 15, 812-821.

(16) Karanjkar, P. U.; Lee, J. W.; Morris, J. F. Surfactant effects on hydrate crystallization at the water-oil interface: hollow conical crystals. Crust. Growth Des, 2012, 12, 3817-3824.

(17) Delroisse, H.; Torré, J. P.; Dicharry, C. Effect of a hydrophilic cationic surfactant on cyclopentane hydrate crystal growth at the water/ cyclopentane interface. Crust.Growth Des. 2017, 17, 5098-5107.
(18) Yoslim, J.; Linga, P.; Englezos, P. Enhanced growth of methanepropane clathrate hydrate crystals with sodium dodecyl sulfate, sodium tetradecyl sulfate, and sodium hexadecyl sulfate surfactants. $\underline{L}$ Crvst. Growth 2010, 313, 68-80.

(19) Zylyftari, G.; Lee, J. W.; Morris, J. F. Salt effects on thermodynamic and rheological properties of hydrate forming emulsions. Chem. Eng. Sci. 2013, 95, 148-160.

(20) York, J. D.; Firoozabadi, A. Effect of brine on hydrate anti agglomeration. Energy Fuels 2009, 23, 2937-2946.

(21) Zerpa, L. E.; Salager, J. L.; Koh, C. A.; Sloan, E. D.; Sum, A. K. Surface chemistry and gas hydrates in flow assurance. Ind. Eng. Chem. Res. 2011, 50, 188-197.

(22) Rosen, M. J.; Kunjappu, J. T. Surfactants and Interfacial Phenomena: Wiley, J. \& Sons, Inc.: Hoboken, NJ, 2012.

(23) Wu, Q.; Zhang, B. Memory effect on the pressure temperature condition and induction time of gas hydrate nucleation. L. Nat. Gas Chem, 2010, 19, 446-451.

(24) Sowa, B.; Maeda, N. Statistical study of the memory effect in model natural gas hydrate systems. L.Phvs. Chem. A 2015, 119, 1078410790.

(25) Duchateau, C.; Glénat, Ph.; Pou, T. E.; Hidalgo, M.; Dicharry, C. Hydrate precursor test method for the laboratory evaluation of kinetic hydrate inhibitors. Enerov Fuels 2010, 24, 616-623.

(26) Stern, L. A.; Kirby, S. H.; Durham, W. B. Peculiarities of methane clathrate hydrate formation and solid state deformation, including possible superheating of water ice. Science 1996, 273, 1843-1848.

(27) Svartaas, T. M.; Gulbrandsen, A. C.; Huseboe, S. B. R.; Sanved, $O$. An experimental study on "un normal" dissociation properties of structure II hydrates formed in presence of PVCAP at pressures in the region 30 to 175 bar-Dissociation by temperature increase. 6th International Conference on Gas Hydrates, Vancouver, July 6-20, 2008.

(28) Anklam, M. R.; York, J. D.; Helmerich, L.; Firoozabadi, A. Effects of anti agglomerants on the interactions between hydrate particles. AIChE J. 2008, 54, 565-574.

(29) Moradpour, H.; Chapoy, A.; Tohidi, B. Phase inversion in water oil emulsions with and without gas hydrates. Enerov Fuels 2011, 25, $5736-5745$

(30) Brown, E. P.; Hu, S.; Wells, J.; Wang, X.; Koh, C. A. Direct measurements of contact angles on cyclopentane hydrates. Enerov Fuels 2018, 32, 6619-6626. 


\section{Effects of a Quaternary Ammonium Salt on the Growth,}

\section{Wettability, and Agglomeration of Structure II Hydrate}

\section{Crystals.}

H. Delroisse ${ }^{1}$, J.-P. Torrél, C. Dicharry ${ }^{1 *}$

${ }^{1}$ CNRS/TOTAL/UNIV PAU \& PAYS ADOUR/E2S UPPA, Laboratoire des Fluides Complexes et leurs Réservoirs-IPRA, UMR5150, 64000, PAU, France

* Corresponding author: christophe.dicharry@univ-pau.fr

SUPPORTING INFORMATION

Supporting Information A:<smiles>CCCCCCCCCCCC[N+](C)(C)Cc1ccccc1</smiles>

Figure S1. Structure of Noramium ${ }^{\circledR}$ DA 50 molecule.

Supporting Information B: Emulsion formation and stability. Because the systems studied composed of water (salted or not salted), oil (CP or n-C8) and a surfactant (DA 50) - are agitated throughout the evaluation of the anti-agglomeration performance they form an emulsion. We determined the type (water-in-oil (w/o) or oil-in-water $(\mathrm{o} / \mathrm{w}))$ of the emulsions formed and evaluated their stability, as these properties are likely to have an impact on the anti-agglomeration performance observed ${ }^{1-3}$. For these experiments, $12 \mathrm{~cm}^{3}$ of aqueous solution with $1 \mathrm{wt} \%$ of DA 50 and with 0 or $4 \mathrm{wt} \%$ of $\mathrm{NaCl}$ were 
placed in test tubes with $28 \mathrm{~cm}^{3}$ of $\mathrm{CP}$ (or $\mathrm{n}-\mathrm{C} 8$ ) at room temperature. Then, the tubes were vigorously shaken by hand for a few seconds and separation of the emulsion was monitored for $180 \mathrm{~min}$. The emulsion stability was determined by measuring the time needed to separate $60 \mathrm{vol} \%$ of the initial aqueous phase. The emulsion type was determined by measuring the conductivity $(\sigma)$ of the system under mechanical agitation. For the system with pure water, $0.25 \mathrm{wt} \%$ of $\mathrm{NaCl}$ were added to the aqueous phase in order to obtain distinct conductivity values for the aqueous and oil phases. If $\sigma \sim 0$, the oil phase was the continuous phase and the emulsion was of the w/o type, and if $\sigma>0$, the aqueous phase was the continuous phase and the emulsion was of the o/w type. The results are summarized in Table S1. The emulsion type and stability were found to be unrelated to the oil (CP or n-C8) used.

Table S1. Stability and type of emulsions formed in the presence of 0 or $4 \mathrm{wt} \% \mathrm{NaCl}$ and $1 \mathrm{wt} \% \mathrm{DA} 50$ for a water:oil ratio of $30: 70(\mathrm{v} / \mathrm{v} \%)$.

\begin{tabular}{lll}
\hline $\mathrm{NaCl}$ & Emulsion type & $\begin{array}{l}\text { Stability }^{\mathrm{a}} \\
(\mathrm{min})\end{array}$ \\
$(\mathrm{wt} \%)$ & & \\
\hline 0 & Oil-in-water & $43 \pm 2$ \\
4 & Oil-in-water & $8 \pm 1$ \\
\hline & \\
\hline
\end{tabular}

Supporting Information C: The interfacial tension (IFT) between aqueous solutions (pure water and DA 50 solutions without and with $\mathrm{NaCl}$ ) and $\mathrm{n}-\mathrm{C} 8$ in the presence of the $\mathrm{CH}_{4} / \mathrm{C}_{3} \mathrm{H}_{8}$ gas mixture was measured in a high-pressure cell with an internal volume of $6.4 \mathrm{~cm}^{3}$. Except the high-pressure cell, the experimental setup was the same as the one shown in Figure 2.

The experimental protocol used for the IFT measurements was as follows. The cell was cooled at $10^{\circ} \mathrm{C}$ and then filled with $4 \mathrm{~cm}^{3}$ of n-C 8 . It was quickly loaded with the $\mathrm{CH}_{4} / \mathrm{C}_{3} \mathrm{H}_{8}$ gas mixture at $72 \pm 1$ bar. Because of the gas solubilization into the oil phase, the cell pressure decreased and then stabilized at 58 \pm 1 bar. The syringe pump was used to form and maintain a small water drop (of a few $\mu \mathrm{L}$ ) at the tip of 
the vertical capillary, which was immersed in the oil phase. The drop shape was analyzed with a computer program that solves the Laplace equation describing mechanical equilibrium under capillary and gravity forces and monitors variations in IFT over time.

To calculate the gravity force, the densities of the water and oil phases at the experiment temperature are needed. The density of the aqueous solution (pure water or surfactant solution) was assumed the same as pure water. The oil density was calculated using a pT-flash calculation.

The measured IFT at 58 bar and $10^{\circ} \mathrm{C}$ (i.e. at a subcooling of about $9^{\circ} \mathrm{C}$ ) are given in Table S2. In the presence of $1 \mathrm{wt} \%$ DA 50 (without and with $\mathrm{NaCl}$ ) or of $0.1 \mathrm{wt} \%$ DA 50 with $4 \mathrm{wt} \% \mathrm{NaCl}$, the drop could not be maintained at the tip of the capillary. This behavior indicates that the equilibrium IFT of these systems was lower than the lowest IFT that can be measured with our apparatus $(\sim 1 \mathrm{mN} / \mathrm{m})$. The IFT values given in Table $\mathrm{S} 2$ show that in the presence of $\mathrm{NaCl}$ and DA 50, the IFT between water and $\mathrm{n}-\mathrm{C} 8$ is drastically reduced. Delroisse et al. (2017) found similar effect of DA 50 and $\mathrm{NaCl}$ on the IFT between water and cyclopentane. ${ }^{4}$

Table S2. Equilibrium interfacial tension (IFT) between water and n-C8 without DA 50, with $0.1 \mathrm{wt} \%$ DA 50, and with $0.1 \mathrm{wt} \%$ DA 50 and $4 \mathrm{wt} \% \mathrm{NaCl}$.

\begin{tabular}{ll}
\hline System (water/n-C8) & IFT (mN/m) \\
\hline Without DA 50 & $50 \pm 2$ \\
$0.1 \mathrm{wt} \%$ DA 50 & $9 \pm 1$ \\
$0.1 \mathrm{wt} \%$ DA 50, 4 wt\% NaCl & $<1$ \\
$1 \mathrm{wt} \%$ DA 50 & $<1$ \\
$1 \mathrm{wt} \%$ DA 50, 4 wt \% NaCl & $<1$ \\
\hline
\end{tabular}




\section{Supporting Information D:}

CP-hydrate morphology in the presence of alkanes. The morphology of the CP hydrates without or with $1 \mathrm{wt} \%$ DA 50 in the presence of 0 or $4 \mathrm{wt} \% \mathrm{NaCl}$ was observed in presence of $\mathrm{CP} / \mathrm{n}-\mathrm{C} 8$ or $\mathrm{CP} / \mathrm{n}-$ C12 mixtures, at a ratio of 50:50 (v/v\%). The snapshots of the hydrates formed are shown in Figure S2.

$\begin{array}{lll}\text { Oil phase } & 50 / 50(\mathrm{v} / \mathrm{v} \%) \\ \mathrm{CP} / \mathrm{n}-\mathrm{C} 8\end{array}$

(a)

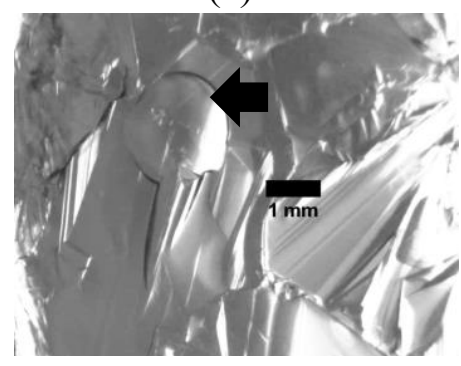

(a)

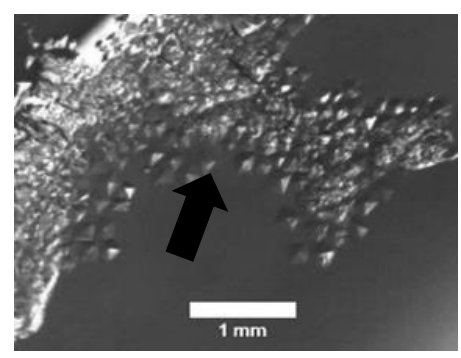

(a)

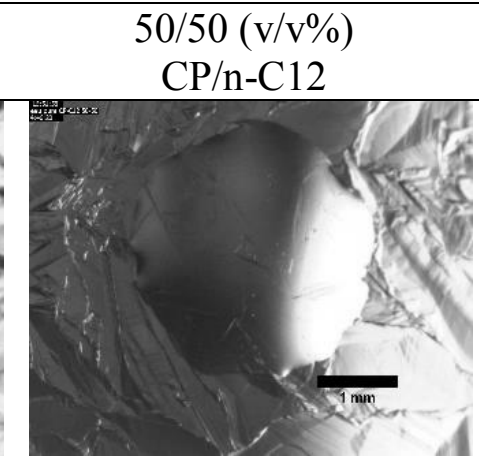

(b)

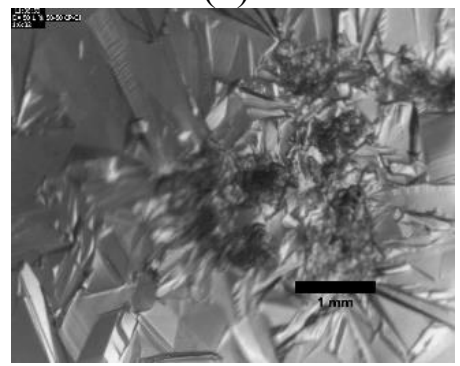

(b)

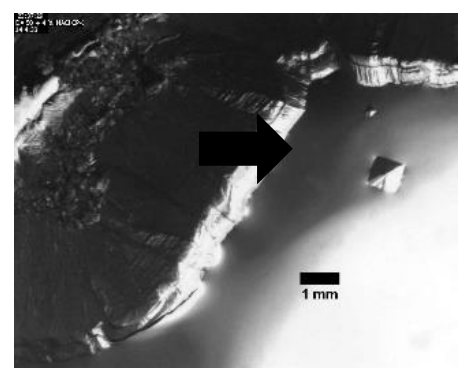

(b)

Figure S2. Snapshots of the CP-hydrate growth at the water/CP/n-C8 or $\mathrm{CP} / \mathrm{n}-\mathrm{C} 12$ interface without surfactant, with $1 \mathrm{wt} \%$ DA 50, and with $1 \mathrm{wt} \%$ DA 50 and $4 \mathrm{wt} \% \mathrm{NaCl}$ at a subcooling of $6^{\circ} \mathrm{C}$.

Without surfactant and without $\mathrm{NaCl}$ (Figures S2.1a and b) and with $1 \mathrm{wt} \% \mathrm{DA} 50$ (Figures S2.2a and b), the water/oil interface was covered with plates of hydrates growing from the seeds added. A drop of the aqueous solution deposited on the hydrate shell spread (black arrows in the snapshots in Figures S2.1 and 2), meaning the shell was water-wettable. Note that the hydrate shell formed in the systems with $\mathrm{CP} / \mathrm{n}-\mathrm{C} 8$ 
or $\mathrm{CP} / \mathrm{n}-\mathrm{C} 12$ grew 3 times more slowly than with pure $\mathrm{CP}$ (see Table S3). With (1 wt $\%$ DA 50 and 4 wt $\%$ $\mathrm{NaCl}$ ) and $\mathrm{n}-\mathrm{C} 8$ or $\mathrm{n}-\mathrm{C} 12$, pyramidal crystals slowly formed during the first hours after the seeding (Figures S2.3a and b). They then agglomerated on the sides of the glass tube, and slowly formed a thick hydrate shell at the interface. The hydrate shell was oil-wettable. Some pyramidal crystals, which remained present throughout the experiment, can be seen in the snapshots in Figures S2.3a and b (black arrows).

Table S3 Lateral growth rate (v) for the systems with an oil phase composed of $\mathrm{CP}$ or $\mathrm{CP} / \mathrm{n}-\mathrm{C} 8$ or $\mathrm{CP} / \mathrm{n}$ C12, without surfactant, with 1 wt $\%$ DA 50, and with 1 wt $\%$ DA 50 and $4 \mathrm{wt} \% \mathrm{NaCl}$, at a subcooling of $6^{\circ} \mathrm{C}$.

\begin{tabular}{lllll}
\hline \multirow{2}{*}{ System } & \multicolumn{3}{c}{$v(\mathrm{~mm} / \mathrm{min})$} & \\
\cline { 2 - 5 } & $100 \% \mathrm{CP} 4$ & $50 / 50 \mathrm{v} / \mathrm{v} \%$ & $50 / 50 \mathrm{v} / \mathrm{v} \%$ & Wettability \\
& & $\mathrm{CP} / \mathrm{n}-\mathrm{C} 8$ & $\mathrm{CP} / \mathrm{n}-\mathrm{C} 12$ & \\
\hline Without additive & $0.21 \pm 0.02$ & $0.054 \pm 0.030$ & $0.033 \pm 0.002$ & Water \\
$1 \mathrm{wt} \%$ DA 50 & $0.11 \pm 0.02$ & $0.033 \pm 0.002$ & $0.032 \pm 0.003$ & Oil \\
$1 \mathrm{wt} \%$ DA 50 and 4 wt\% NaCl & & $0.002 \pm 0.001$ & $0.005 \pm 0.002$ & Oil \\
\hline
\end{tabular}

\section{Anti-agglomeration performance of DA 50 evaluated in the agitated batch reactor in the presence}

of $n-C 8$ or $n-C 12$. Figure S3 shows the variation in the torque $(C)$ and temperature $(T)$ versus time (t) for the system water/CP/n-C8 or n-C12 without additives or with $1 \mathrm{wt} \%$ DA 50 and 0 or $4 \mathrm{wt} \% \mathrm{NaCl}$. Without DA 50 or $\mathrm{NaCl}$ (Figure S3.1), the hydrate formation process caused a first increase in the torque signal up to 0.16 N.m, then a second increase up to 0.7 N.m (maximum torque value). The reactor was opened when the hydrates had finished forming, and we observed that the system was composed of a hydrate plug filling the entire reactor and no liquid phase. 


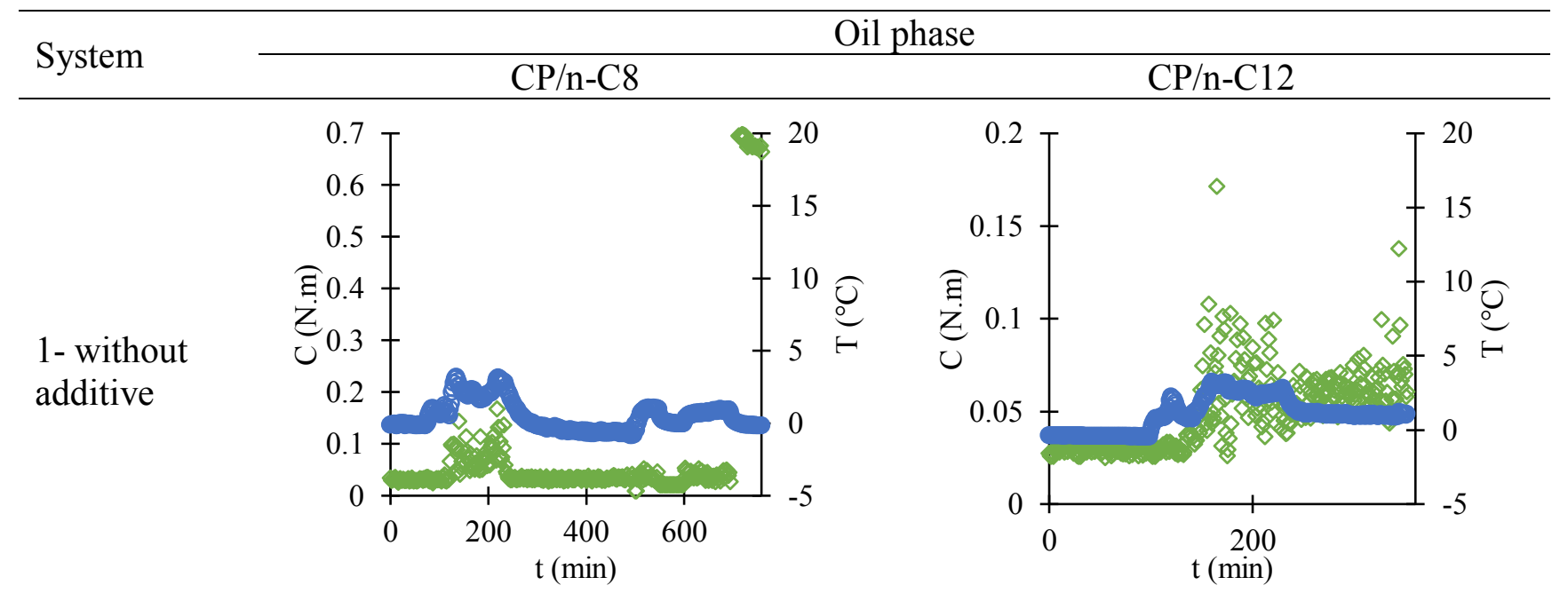

(a)

(b)

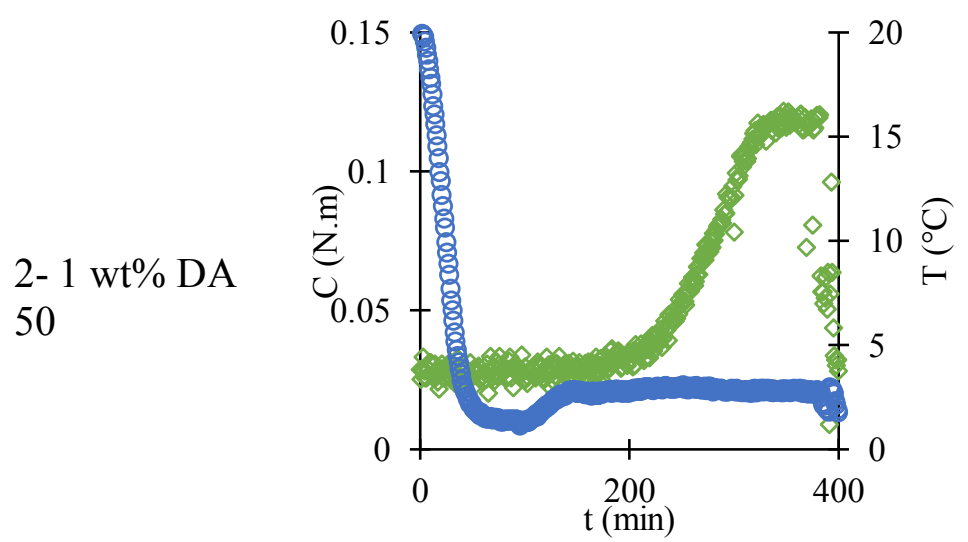

(a)

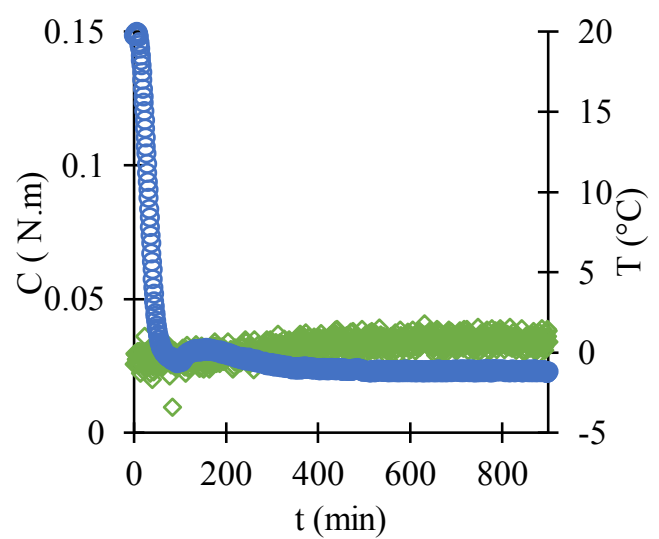

(a)

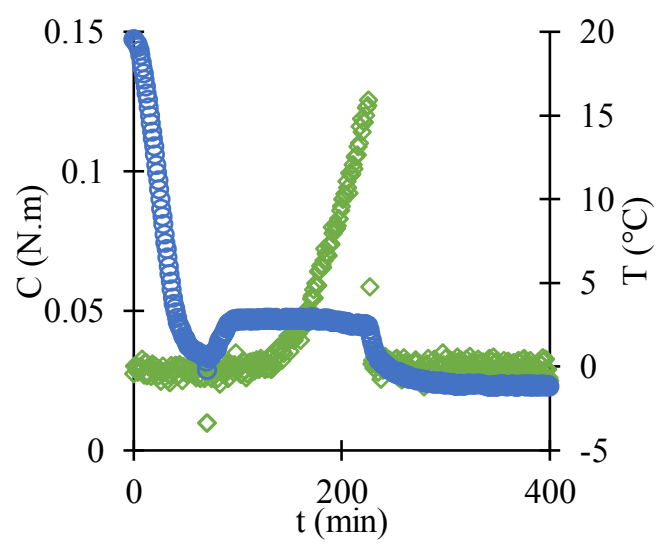

(b)

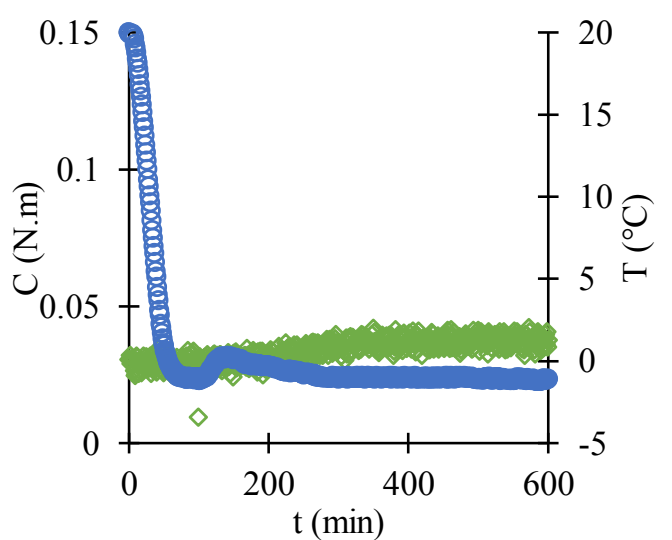

(b)

Figure S3. Torque $(\mathrm{C})(\diamond)$ and temperature $(\mathrm{T})(\mathrm{O})$ versus time $(\mathrm{t})$ during the formation of CP hydrates without surfactant (1) or with $1 \mathrm{wt} \%$ DA 50 (2), or with 1 wt $\%$ DA 50 and 4 wt $\% \mathrm{NaCl}$ (3) with CP/n-C8 (a) or $\mathrm{CP} / \mathrm{n}-\mathrm{C} 12$ (b) as the oil phase at a subcooling of $6^{\circ} \mathrm{C}$. 
With DA 50 (Figure S3.2), the torque increased with the hydrate growth up to 0.12 N.m before dropping to the baseline. The reactor was first opened when the torque signal increased $(\sim 0.08$ N.m). The system was composed of a jelly-like material. After the drop in torque, the reactor was opened a second time. The system was composed of hydrates agglomerated on the agitator and the walls of the reactor. Note that the hydrate formation was slower than for the system with pure $\mathrm{CP}$ and the temperature peak caused by the hydrate formation was lower. The slower hydrate formation kinetics are consistent with the slower lateral hydrate growth rates measured in the morphology experiments at the water/oil interface. With 1 wt $\%$ DA 50 and $4 \mathrm{wt} \% \mathrm{NaCl}$ (Figure S3.3), the hydrates grew very slowly causing a slight increase in the torque (from 0.025 to $0.035 \mathrm{~N} . \mathrm{m}$ ). At the end of the experiment, we opened the reactor and saw that the system was composed of a mixture of emulsion and hydrate particles. The conversion could not be determined (no supernatant oil phase recoverable at the end of the experiments) for any systems, but the water-to-hydrate conversion seemed to be incomplete.

\section{Supporting Information E:}

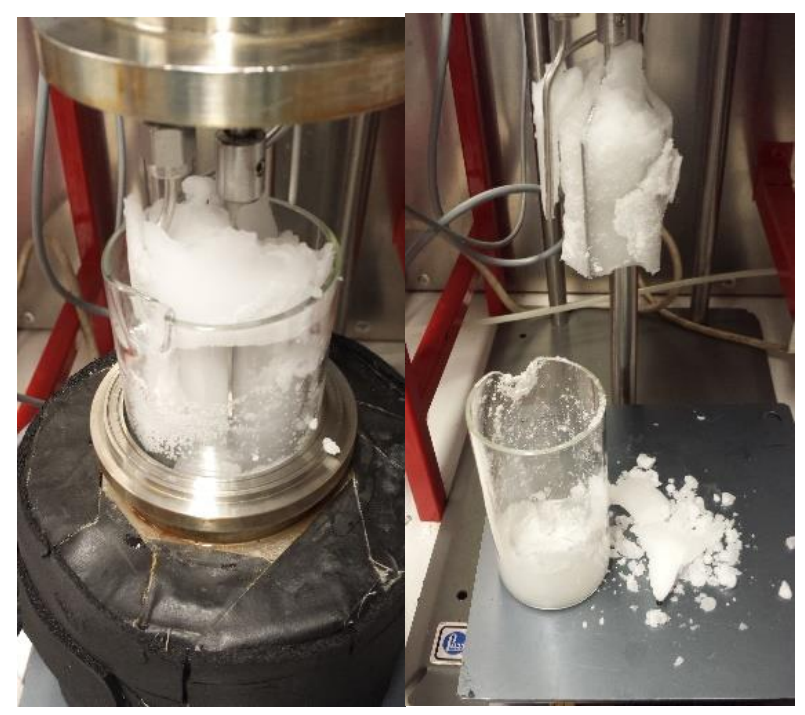

Figure S4. Snapshots of the state of the system after hydrate formation without surfactant. 


\section{Supporting Information F:}

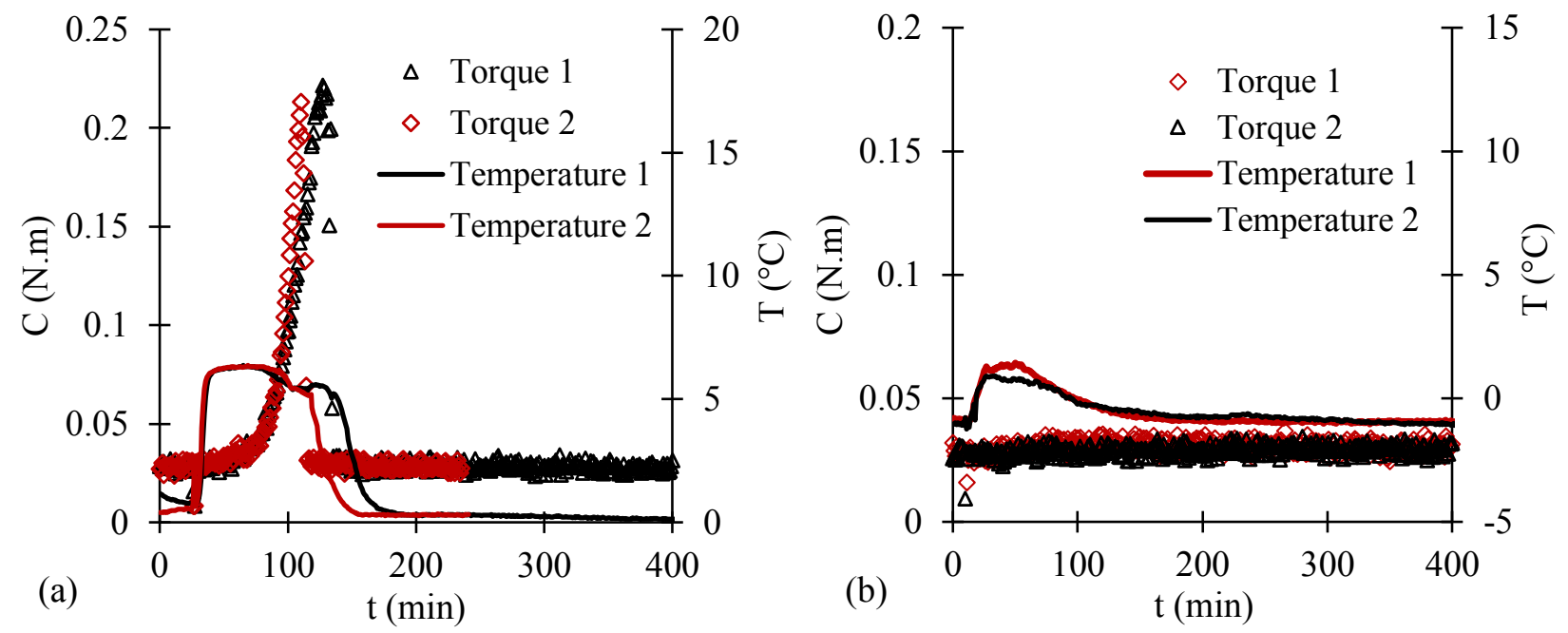

Figure S5. Torque $(\mathrm{C})$ and temperature $(\mathrm{T})$ versus time $(\mathrm{t})$ during the formation of $\mathrm{CP}$ hydrates with 1 wt\% DA 50, without (a) or with $\mathrm{NaCl}(\mathrm{b})$, at a subcooling of $6^{\circ} \mathrm{C}$. Each experiment was repeated twice. $\mathrm{t}=0$ corresponds to the seeding of the system.

\section{Supporting Information G:}

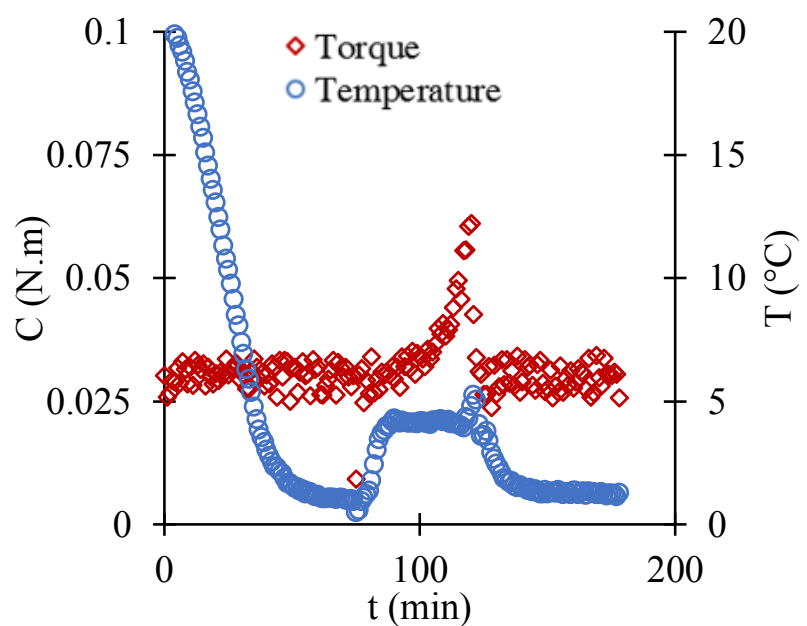

Figure S6. Torque (C) and temperature $(\mathrm{T})$ as a function of time (t) throughout the formation of $\mathrm{CP}$ hydrates with $1 \mathrm{wt} \%$ DA 50 at a subcooling of $6^{\circ} \mathrm{C}$. The final volume fraction of hydrate is $26 \%$. 


\section{REFERENCES}

(1) Huo, Z.; Freer, E.; Lamar, M.; Sannigrahi, B.; Knauss, D. M.; Sloan E. D. Hydrate plug prevention by anti-agglomeration. Chem. Eng. Sci. 2001, 56, 4979-4991.

(2) Zanota, M. L.; Dicharry, C.; Graciaa, A. Hydrate plug prevention by quaternary ammonium salts. Energy Fuels 2005, 19, 584-590.

(3) York, J. D. and Firoozabadi, A. Comparing effectiveness of rhamnolipid biosurfactant with a quaternary ammonium salt surfactant for hydrate anti-agglomeration effect of brine on hydrate antiagglomeration. J. Phys. Chem. B 2008, 112, 845-851.

(4) Delroisse, H.; Torré, J.-P.; Dicharry, C. Effect of a hydrophilic cationic surfactant on cyclopentane hydrate crystal growth at the water/cyclopentane interface. Cryst. Growth Des. 2017, 17, 5098-5107. 